\title{
$7 \quad$ Traversing Myriad Trails: Tracking Gender and Labour Migration across India
}

\author{
Indrani Mazumdar ${ }^{1}$ and Indu Agnihotri ${ }^{2}$
}

\begin{abstract}
$^{3}$
This chapter argues that the effacement of gender in macro-analyses of internal migration in India is based on the collective inability to delineate the contours of female labour migration from the official databases. While critiquing the monocausal approach to migration which overwhelmingly privileges social over economic reasons in female migration, the chapter essays a gendered macro-view of labour migration in India, for which new methods of approaching the data of the most recent macro-survey on migration in India (2007-08) are applied. The authors argue that the migration pattern is enhancing structural gender inequalities in the labour market. While the domination of services and industry in male migrant employment has contributed to a degree of diversification in the structure of the male workforce away from agriculture, the same is not the case for the female workforce.

Drawing on primary surveys conducted across 2009-20II, the chapter argues that a meso-level view shows a predominantly long- and medium-term migratory pattern among upper-caste women to have brought hitherto home-bound women into diversified employment in more white-collar services. On the other hand, short-term and circulatory migration involving hard manual labour with limited scope for social advancement predominates among women from traditionally disadvantaged castes/tribes. A distinctively gendered process of concentration among migrant women in paid domestic work, however, cuts across caste hierarchies. While women workers' involvement in family decisions to migrate and 'autonomous' migration by women is not insignificant, a broad tendency towards their concentration in a narrow range of occupations is identified. It is argued that the temporary nature of much of employment leads to a pullback to villages, despite agrarian crisis.

In foregrounding the intersections between caste, class, and gender inequalities, and arguing that such inequalities are being reconfigured through migration, the chapter draws on the perspective of the women's movement in India. It is argued that the absolute reduction in employment for women during the most distinctive phase of high GDP growth in India posits the need for more redistributive and equalizing growth as the path forward for social justice.
\end{abstract}

Keywords: India, labour migration, gender, typology of migration, circulatory migration, medium-term migration, occupational diversification, caste, tribe, women's movement.

\subsection{Introduction}

The most recent macro-survey of migration in India (National Sample Survey [NSS], 2007-08), estimated

1 Indrani Mazumdar is a Senior Fellow at the Centre for Women's Development Studies, New Delhi, India.

2 Indu Agnihotri is the Director of the Centre for Women's Development Studies, New Delhi, India.

3 This paper is based on the findings of an IDRC-funded project entitled "Gender and Migration: Negotiating Rights - A Women's Movement Perspective", project number I03978-00I. that some 327.7 million people in the country were internal migrants. Eighty per cent of them were female, and migrants accounted for nearly 29 per cent of the country's population. Defined as those who have changed their usual place of residence (UPR) any time in the past, migrants encompassed 48 per cent of the country's rural female population and 46 per cent of urban females. A decade and a half before, in 1993 , the rates of female migration were much less, at 40 per cent of the rural and 38 per cent of urban female populations. In contrast to such substantial increases in female migration rates in both rural and urban 
areas, migrants in the rural male population of India declined from six per cent to five per cent between 1993 and 2007-08, and increased by only two percentage points from 24 per cent to 26 per cent in urban India. $^{4}$

Despite such overwhelming numerical preponderance, the female migration data have hitherto been dismissed as irrelevant to development-oriented analysis of migration in India because the proportions of women identified as moving for employment-related reasons is exceedingly small. The majority of women are shown as migrating for marriage, unlike men, who are shown as moving predominantly for employmentrelated reasons. Several decades of data on migration have thus presented a largely unchanging picture of women migrating for mainly social reasons and men for economic reasons. The net result has been an established tendency among policymakers and analysts towards using male migration as the prime socioeconomic indicator for trends in migration in India, at the cost of gendered analysis and a complete statistical silence on the scale, dimensions, and patterns of female labour migration. This chapter attempts to break such a silence, to lay out some of the key gendered features of labour migration in India, and to examine their social trajectories from a women's movement perspective.

From the end of the I990s, in the midst of the unprecedented agrarian crisis that had unfolded within a decade of the structural shift in India's policy regime towards liberalization, mass-based women's organizations began reporting new forms of distress-driven migration by rural women in search of work -largely short-term, involving greater distances and different from traditional migration routes, sometimes without family members, and in conditions of heightened vulnerability (CWDS 2005; Ghosh 2005)..$^{5}$ By 2005, leaders and activists of the women's movement in India were chafing against the lack of official record of the "armies of women migrating in search of work" (Karat 2005). A few micro-studies from an earlier period had indeed drawn attention to the significant proportion of women in seasonal short-term labour migration, particularly in rural areas (Rao 1986; Banerjee/ Ray I99I; Karlekar 1995; Teerink 1995). Mostly regionor even community-specific, these studies had also

4 Government of India, National Sample Survey Office, Reports nos. 430 and 533.

5 See CWDS (2005): "Report of Seminar on Globalization and the Women's Movement in India”; at: <http:// www.cwds.ac.in/OCPaper/GlobalisationReport.pdf $>$. contributed to making available fairly detailed descriptions of some relatively long-standing migration patterns that could not be extracted from the macrodata. However, they rarely connected with the policy frameworks or the macro-context except in over-specific or over-general terms, and the impact of post-liberalization developments remained outside their frame. ${ }^{6}$ The countrywide breadth and scope of contemporary labour migration by women in both rural and urban areas thus remained invisible and eluded broader analysis. Consequently, there was a sharp disconnect between the experiences and conditions highlighted by the women's movement in India and the information and database on migration drawn on by policymakers or even concerned academics.

To meet the demand of the women's movement for better documentation of labour migration by women, the Centre for Women's Development Studies (CWDS) undertook a major research project on gender and migration in India, involving a critical engagement with the macro-data as well as extensive primary fieldwork, including a series of questionnairebased surveys in villages, towns, and cities across twenty of India's twenty-eight states between 2008 and $20 \mathrm{II}^{7}$ Drawing on the CWDS's research, this chapter essays a gendered macro-view of labour migration in contemporary India. It outlines some of the methodological issues and questions that emerged from probing the official data on migration, including additional information made available in the latest migration survey of the National Sample Survey (NSS). This is then juxtaposed with some of the insights and findings from the fieldwork and the surveys that have been consolidated as a meso-level approach to the types and modes of female labour migration in contemporary India. ${ }^{8}$

6 There were several excellent micro-studies on women's migration in the I980s, not all of which were published. Most of these studies have been referred to in: SchenkSandbergen (1995).

7 The CWDS research team for this project comprised the authors of this chapter and Dr N. Neetha, assisted by Shruti Chaudhry and Taneesha Mohan. The support of the International Development Research Centre of Canada (IDRC) which made this project possible is gratefully acknowledged.

8 Over a period of 24 months commencing January 2009, surveys with the pair of detailed and structured questionnaires were conducted across twenty states, covering 5,007 individual migrants and 5,558 households. These were drawn from village surveys as well as sectorbased surveys. 
As mentioned, the study approaches the subject of migration from a women's movement perspective. Many eyebrows may be raised at such an assertion, ranging from those who would question such declared partisanship to those who query the notion of $a$ women's movement, given the diversity of ideologies and sectional interests that lay claim to the movement (or movements as they may say). A few words of clarification are therefore in order. From our point of view, what defines a movement perspective is its premise of the mobilization of women - in their independent but not necessarily individualistic capacities as a social movement. Such a perspective is thus distinguished from those of general development administration or even the many non-governmental institutions engaged in 'beneficiary'-oriented scheme delivery that inherently involves some form of patronclient relationships. That such a social movement would contain several strands of opinion is inevitable, but while a variety of opinion leaders and ideological emissaries have initiated processes of mass mobilization, the social movement that has been so generated in India since the late I970s has an aggregated force that is compellingly greater than its individual strands. There is an accumulating reservoir of experience of both plurality and commonality in the history of the women's movement in India, which is a major resource for the grounding of our perspective on gender and migration. ${ }^{9}$ Analytical assumptions of a division into autonomous vs. party-led women's organizations have underwritten much of the academic discourse on the contemporary women's movement in India. However, our understanding is in line with the argument that "in fact the history of the movement shows that no such clear dichotomy ever existed at the level of issue-based understanding...neither the 'autonomous' nor the mass organizations had a fully unified understanding, either amongst or between themselves" and on most issues "there was a criss-

9 There are of course several groups and organizations active in the women's movement in India, not all of whom organize on a mass scale. Yet alliances and unities on several common issues have become standard practice. The most prominent and sustained national level joint front, consisting of organizations with different political affiliations that evolved out of the movements of the early I980s, was initially called the seven sisters, although the number of components has varied across time. Many differences have cropped up in the course of the movement since then, and the organizational compositions of the various alliances have continuously been refashioned on an issue-to-issue basis. crossing between the two categories" (Agnihotri 200I). It is out of such an accumulating habit of practice of unities within differences and debates, combined with mass engagement, that the women's movement in India has continued to grow, not only in the public arena but also at the level of analysis.

That the programme of the women's movement is at one level multi-class and geared towards equality for women as women is axiomatic and does not perhaps require much elaboration. Less self-evident, but equally compelling, is the Indian movement's instinctive alignment with women as members of social classes who can broadly be termed peasants and workers, including a range of petty producers/sellers/ service providers in artisanal as well as modern technology-based industry and services. In a country mired and fissured by extreme levels of mass poverty and wealth, where women's confinement, purdah, and gross inequalities - jostling with the violences of superimposed capitalist modernity - define much of our social context and render constitutional mandates of equality and social justice as yet insubstantial, it is women from these social classes who have provided the anchor to the countrywide women's movement and a durable social base to the popular female-led surge on issues related to women's rights and conditions from the late I970s to the present. One can link the quite remarkable expansion of the contemporary women's movement in India to the inextricably entwined phenomena of a spreading tide of organic female ferment across classes and community categories on the one hand, and on the other, the more conscious and sustained attempts to extend the representative base of women's organizations. In the process, discrimination based on caste or social group and the differentiated/specific conditions of women as dalits and tribals ${ }^{10}$ and even as members of religious minorities have emerged as focal issues for the movement more than ever before. Not accidentally, but in fact driven by its expanding social base and perspective, the women's movement emerged in the forefront of the struggle against neo-liberal doctrine and its adverse effect on food security and the labouring

10 'Dalit' refers to historically disadvantaged caste communities stigmatized as 'untouchables". They are officially designated as 'Scheduled Castes' in the Indian Constitution. Similarly 'Tribes' refer to communities whose social organisation falls outside the mainstream caste based social order and whose livelihood and location was traditionally forest based. They are designated as 'Scheduled Tribes' in the Indian Constitution. Muslims constitute the largest religious minority in India. 
poor in India. It was the first to oppose the divisive practice and restrictive principle of narrow 'targeting' of subsidized food at only those officially declared below the poverty line (as distinct from the general poor). Its early arguments for adherence to the universal principle of food security were later taken up by various other rights-based groups. As such, as distinct from mere singularity of individual female identity, a contemporary women's movement perspective in India brings to the field of migration studies a perspective that is for women as women, as peasants and workers, as members of particularly oppressed communities, and as citizens, invoking general concepts of gender equality, redistributive justice, and freedom from poverty and subordination, but especially grounded in the cumulative experience of resurgent mass engagement. ${ }^{11}$

At the same time, in relation to both the debates and actualities of women's rights in India, it is well to remember that they have been shaped through multiple inequalities and through social and economic policies and developments on which the women's movement has had, as yet, only peripheral impact. To our minds, empirical research that draws its perspective from the women's movement must thus interweave into its enquiry questions based on the immediate issues and experiences of the movement while maintaining an overarching framework of strategic questions. For us, combining and referencing short-term issues with long-term strategic perspectives is supremely important. One reason is an awareness of the broad historical tendency in structurally unequal societies for every relative advance in women's status/conditions to simultaneously contain elements of relative regression, a point that has emerged sharply in the course of this study. Secondly, we believe that only through comparing our enquiry results against both short-term gains and longer-term strategic objectives can a more adequate and purposive understanding of gendered social processes in relation to migration be developed. The linking of the concrete or immediate issues to strategic objectives has enduring value as a guiding method and perspective for the women's movement and its researchers. Such an understanding informs and frames the issues and questions in relation to gender and migration in India that are discussed in this chapter.

11 The women's movement in India has a history stretching back to the pre-independence era. Nevertheless, its resurgent and clearly female-led mode from the late I970s marked the opening of a qualitatively new phase.
In the following sections, a perspective discussion on gender, migration, and development paradigms is initiated, along with a critical engagement with the gender-insensitive orientation of the official macrosurveys of migration in India. This is followed by a gendered macro-view of internal labour migration drawing from the 2007-08 migration survey by the National Sample Survey Office (NSSO). In approaching labour migration, a specific focus on paid workers has been maintained with the objective of highlighting the labour market outcomes of migration and embedded inequalities. The chapter then moves on to discussing some of the consolidated findings of the micro-surveys conducted by the CWDS. The scope of the CWDS surveys and methodology are first outlined. This is followed by description and analysis of various types of migration based on a typology developed by the study. Correlations are then drawn between types of migration, occupations, and caste hierarchies. The findings of the primary surveys cover occupational changes effected through migration and modes and manner of migration. The conclusion summarizes some of the key findings and questions laid out in the chapter.

\subsection{Gender, Migration, and Development Paradigms: Interrogating the Database}

Approaches to migration in development discourses and theories have been, in the main, preoccupied with transition from an agrarian to an industrial or even post-industrial capitalist social and economic order, a transition for which rural-to-urban migration is often seen as a rough proxy. A common underlying thread running through otherwise divergent economic policy paradigms in India, (i.e., the earlier state directed development policy [I953 to I985] and the later market supremacist approach [I99I to the present]) is the broad understanding that the migration process leads to some form of settlement at a particular destination (probably urban), usually accompanied by occupational/sectoral change (from the low productivity 'traditional' agricultural sector to the high productivity 'modern' industrial sector), enhanced incomes, and perhaps some degree of social mobility. In actuality, the experience has been of a relatively slow rate of urbanization (Kundu 1999), the continuance of agriculture as the majority employment, and the expansion of more circular forms of migration in, to, and around rural as well as urban ar- 
eas. ${ }^{12}$ Temporary and circular migration appear to have further gained ground in the face of the increasing rather than decreasing weight of unorganized/informal and intermittent forms of employment in rural and urban areas, and by the unsettling and shrinking of more durable organized sector employment (NCEUS 2007). As such, the assumptions and prognostications of early development theory's approaches to migration have long ceased to be really tenable in India.

Circular movements of labour were brought into the debates on migration not from analysis of the macro-data, but through a body of work drawing primarily on qualitatively inclined anthropological research and micro-surveys. This body of work drew attention to the significant proportions of women in short-term labour migration, particularly in rural areas (Banerjee/Ray I99I; Karlekar I995; Teerink I995). National data sets have, however, been slow to respond to research on circular, seasonal, and shortterm migration and have largely remained anchored in what has been called a 'permanent settlement paradigm'. The welcome recent addition of a separate category of short-term migrants in the 2007-08 migration survey by NSSO, as also the inclusion of an additional question on temporary migration for the UPR-defined migrants, is still dogged by definitional weaknesses that persist in excluding a large proportion of circular migrants, particularly those whose annual or perhaps more than annual migratory cycles exceed six months. It is also true that the official migration data based on change of residence relate primarily to population movements, in contradistinction to development or economic theories of migration which are primarily based on labour migration (Srivastava 2005), and there are genuine difficulties encountered in trying to distinguish between the two.

Nevertheless, the data on migration for employment (as the reason for migration) have long been thought to approximate the levels of economic/ labour migration. We believe that it is the monocausal approach (i.e., the attribution of a single reason for migration) followed by the national macro-surveys

12 The micro-studies on circular migration are too numerous to be cited here. It may be noted however, that in I99I, the National Commission on Rural Labour (NCRL) estimated the number of circular migrants in rural areas alone as around Io million including roughly 4.5 million inter-state migrants and 6 million intra-state migrants. Prominent in this research on circular migration or 'labour circulation' is the work of Jan Breman (I996), focused on the state of Gujarat and covering both rural and urban areas. that has been a major factor in camouflaging, under apparently non-economic social reasons, at least some economic/labour-based decisions in women's migration. For example, some implicit or actual labour migration by women may appear in the data as marriage migration or as other forms of associational movement by women simply because the two may coincide, but the social reason is presumed to be allimportant. Even where women of a migrant family enter the paid or income-earning workforce in their individual capacity at any given destination, it is still possible that marriage or family movement would be given as the reason for migration. An underestimation of female migrant workers thus appears to be inbuilt into the data.

A hidebound separation of economic reasons and social reasons for migration, implicit in the monocausal framework, is questionable on several counts. A preliminary question arises as to how such a separation could ever work in India, which is characterized by diverse levels of social organization; where petty production or 'self-employment' still accounts for the major part of the workforce, where several elements of socially reciprocal as well as production relations based on a feudal hierarchy and exchanges of a subeconomic nature persist, and where all the above are linked to the concentration of a large part of the female workforce in various forms of family production or family labour without any individual incomes or control over family income (unpaid labour). This question is relevant for all neo-classical development theory and its models, which tend to view a range of discrete social classes and categories only as labour in relation to capital, in either actual or potential terms (with gender at best as a subset of or associated with such labour). This blindness is notwithstanding a whole series of public policy devices in India that recognize and respond explicitly and implicitly to different social classes and categories such as peasants (or farmers to use the non-class term that has gained currency), landless and predominantly dalit labour in an agrarian social setting, artisans, forest dwellers/tribals, and nomadic communities, among all of whom only some have made a transition to a direct relationship with capital as labour. Even women have been brought in by policies and programmes, as a specific constituency for individual or group-based income generation activities. We would argue that multiple and variegated reasoning and decision-making are involved in the migration process, straddling both social and economic motivations or compulsions, regardless 
of whether migration is undertaken by individuals, families, households, or communities.

Further, circulation between sectors is widespread, since the wages of many of those employed in 'modern' (usually urban) industry or services do not cover the cost of social reproduction of the workers and their offspring/families, which then continues to be borne in part by rural peasant-based subsistence activities. In such cases, a difficulty exists in placing social categories and indeed even individuals as economic agents into an analytical frame based only on economic theories and categories that are derived from developed capitalism. These problems are not of India alone, but resonate through the developing world. Some of these difficulties have found expression in the evolution of the idea of an informal sector/economy, broadly characterized by a large number of selfemployed including family help, low income returns to labour, and the absence of formal social security and legally enforceable contracts. ${ }^{13}$ Despite several definitional disputes, the expanding size of the informal sector/economy rapidly acquired universal acceptance. It could no longer be conceived of as a 'residual category' in developing countries, as was initially argued by many economists. ${ }^{14}$ The delineation of informality was however dogged by questions as to whether the informal nature of the enterprise and self-employment should be taken as its defining feature or whether insecurity and lack of social protection in employment relations should be used for identifying an informal sector/labour. In India, such debate has moved towards decisive settlement by including both (NCEUS 2007). Nevertheless, to us, it appears that the complete jettisoning of the much criticized agriculture/industry/service sector-based frame of early development theories in favour of just a formal/informal divide poses additional problems rather than resolves them, and leads to an evasion of the agrarian question in India. Consequently, although the informal sector debates have indeed made a signal contribution to highlighting the poor conditions of work and the absence and need for social security provisions for the numerically extremely large, heterogeneous but essentially unorganized workforce, they have added little insight into the contemporary agrarian crisis, a crisis that activists in the women's

13 Three decades of debates and issues of conception related to the informal sector are discussed in Bangasser (2000).

14 See Kundu (1999) for a discussion on the difficulties of treating the informal sector as a residual category. movement instinctively perceive as central to understanding women's migration in India today.

Finally, there is the question of the presumption of individual units of labour in the wage economy. Anthropological research has long drawn attention to the circulation of family units or male/female pairs for wage labour in some industries/activities that are virtually completely reliant on migrants. For example, millions of migrant workers are recruited in pairs (jodis) or family units by contractors for brickmaking across the country and for harvesting sugar cane across large areas in western and southern India. ${ }^{15}$ Where direct piece rates are paid for the output of collective units of labour, whether of pairs, families, or ad hoc gangs, conceptual difficulties regarding the basis for the calculation of individual wages are inevitable, although disputes often remain hidden by social conventions. The point is that individual units of labour are not always clearly measured or as universal as is assumed by the employment and migration data and indeed even by the laws related to labour.

In sum, Indian government data and much associated work on migration in India reflect a permanent settlement paradigm, a monocausal approach to migration that tends to a rigid distinction between economic and social reasons for migration, a lack of focus on circular modes of labour migration, and a flattened-out conception/definition of work/employment that is purely based on the individual labour unit. Such a perspective makes the macro-data conceal many important features and trends in relation to labour, gender, and migration that operate in reality in India.

At the same time, many questions that the macrodata raises have not received due attention. We may begin by flagging the most striking feature of the data on enhanced female migration: the phenomenal increase in marriage migration rates in rural India. According to the NSS figures, the proportions of women migrating for marriage increased from 25 per cent of the rural female population in 1993 to 38 per cent in I999-2000 and then to 44 per cent in 2007-08. Increased rates of rural marriage migration is confirmed by census data for the I990s, foregrounding an immediate question as to what processes have led to a substantial rise in migration for marriage in rural areas. ${ }^{16}$

15 For such migration in Maharashtra, see Teerink (1995); and for Gujarat, Breman (1996) and Mosse, Gupta, Mehta, Shah, Rees (2002). For Tamilnadu and Karnataka, we have drawn on our own field observations. 
Running parallel to the remarkable increase in rural female marriage migration is an equally remarkable decline in rural female work participation rates from 33 per cent in 1993-94 to 29 per cent in 2007-08 and further to 26 per cent in 2009-IO. ${ }^{17}$ While rural employment for women is showing signs of acute constriction, urban female work participation rates too have declined from 15.5 per cent in $1993-94$ to 13.8 per cent in 2007-08 and remained the same in 2009-IO. Obviously the narrow base of urban female employment has not been offering much relief from constriction in rural areas. The most recent employment survey has revealed the shocking reality that not merely have the rates of women's work participation declined, but between 2004-05 and 2009-IO, some 2I million women were actually eliminated from the country's workforce. During this quinquennium, agriculture saw an absolute reduction by more than 20 million women workers, manufacturing by more than 3.5 million, and services by more than I.I million, with only construction showing some increases in employment for women (Mazumdar/Neetha 20II).

The experience in India has thus been conclusively contrary to the expectations of expanding employment opportunities and demand for women workers under a liberalized policy regime (the so-called femini-

16 A similar increase in urban marriage migration rates in the NSS surveys is not confirmed by the census of $200 \mathrm{I}$. Currently census data for $201 \mathrm{II}$ is still awaited. Till then we would have to go along with the census evidence for increased marriage migration in rural areas alone. Given the historical basis of settlement, community, and social and land relations in the villages of India, the camouflaging of labour migration under marriage seems less likely in rural areas in comparison to urban, although unsettled questions remain as to whether women who enter the casual wage economy in the village into which they marry or women who marry peasants who have settled in a new village should be considered labour migrants.

17 Work participation rates given here are all on the basis of usual status principal+subsidiary workers (UPSS), as defined in NSS Employment Unemployment Surveys. We may note that for female work participation, the NSS is better able to capture women's work than the census and so generally shows higher levels of female work participation. Generally, the large quinquennial rounds of the NSS, such as for 1993-94, 1999-2000, 2004-05, and 2009-IO, provide the more authoritative figures for employment in comparison to the thinner rounds in between. We have referred also to the medium large mid-quinquennial round of 2007-08, since it ran in tandem with the migration survey, which was not conducted in either 2004-05 or 2009-IO. zation of labour). Rather, it points to the unfolding of a major employment crisis, whose effects have been most sharply felt by rural women. Although a political response to the rural employment crisis indeed came in the form of the enactment of the National Rural Employment Guarantee Act, 2005, the social implications of its gendered features and multi-sector nature have yet to be adequately explored or incorporated in approaches to migration.

Given the focus on labour migration in this chapter, detailed discussion of increased marriage migration rates is not possible. Nevertheless, we should briefly touch upon findings that point to the need to recognize that developments in the sphere of women's work and employment crisis are indeed closely interlinked with social processes including enhanced marriage migration. An important issue through which the two become linked is dowry. Historical explorations of the spread of dowry indicate that the marginalization of women's traditional work in subsistence agriculture induced by colonial commercialization of agriculture had been a factor in the replacement of bride price by dowry in many communities in the lower echelons of the social order, where dowry was not earlier a traditional practice (Sheel 1997). Contemporary movement experiences and other studies of women's work indicate similar processes during the period of policy emphasis on marketdriven growth. Detailed micro-studies have shown that the shift from more female labour-intensive food and subsistence activities to more market-oriented and indeed more mechanized agriculture in the 1990s had been accompanied by a reduction of work availability for rural women (Rawal 2006). Women's movement documents point to a surge in the expansion of dowry into communities where bride price was more common, even some years ago (AIDWA 2003).

Further, a decline in the availability of common property resources for subsistence, particularly in mineral-rich areas of tribal concentration - where corporate-driven privatization has been particularly promoted - has had implications for many social arrangements, inducing a search for dowry-based accumulation through marriages outside local boundaries. ${ }^{18}$ Qualitative case studies of cross-regional marriages in various parts of the country show inability to raise dowry to be a prominent reason for parents to arrange or accept dowry-less marriages for their daughters outside traditional community/language/

18 See Menon and Vadivelu (2006) for the status of common property resources. 
culture/regional marriage boundaries, often in distant and culturally alien territory (Chaudhry/Mohan 20II). The expansion of dowry has generated criss-crossing responses all feeding into widening the search for marriage partners and increasing migration for marriage. In our view, the key issue propelling such interlinked processes is greater marginalization of women's work including marginalization of economic returns from their unpaid work for families, which has been further aggravated by the gendered nature of the employment crisis in India. It all, in a sense, foregrounds the centrality of the demand for independent paid work/employment and equality in the labour market as the way forward for women. It is such a perspective that underlies our approach to labour migration in contemporary India.

\subsection{Gendering the Macro-view on Labour Migration in India}

Deriving a macro-view on labour migration in India from statistics based on population movement inevitably requires a series of exercises that are tedious for both researchers and readers. For a gendered view, derivation is even more complicated because of the inclusion of unpaid labour in the workforce data, which in the case of women is particularly large. As mentioned earlier, a vast reservoir of women's work or economic activities, particularly in an unpaid form, is still largely contained within the family. Where and how such forms of work/labour fit into an understanding of what historians, development economists, and even anthropologists call labour migration is a question that necessarily troubles any gendered approach to labour migration. We have already argued that unpaid work by women (whether in the sphere of production or of social reproduction), needs recognition as a reason for migration. Nevertheless, a question remains as to whether the concept of labour migration per se could or should include such types of unpaid labour-based migration within its ambit.

From a women's movement perspective, a degree of ambiguity on this question is perhaps inevitable in the present social and economic context. At one level, as feminist economists pressing for rethinking 'the Economy' have argued, the unpaid 'care economy' in which people "produce services for their families, friends and neighbours on the basis of social obligation, altruism and reciprocity" (which encompasses a substantial part of women's work) also needs to be taken into account along with the 'commodity econ- omy'. And further, although unpaid care work may be outside the production boundary, its operation has implications both for human well-being and for what goes on inside the production boundary. It affects the quantity and quality of labour supplied to production and the quantity and quality of goods demanded from production (Elson 200I). There is thus a strong case for special attention to the role of unpaid labour in migration, particularly for public policy in relation to social reproduction activities. It has indeed found expression in the Indian women's movement's longstanding activism and demand for public provisioning of basic civic amenities - water, toilets, ration cards, access to health, shelter/housing conditions, etc. - for migrant worker families, particularly in urban areas; for such purposes, the distinction between unpaid work that falls within or outside the production boundary would actually be immaterial.

On the other hand, it cannot be forgotten that the patriarchal family context necessarily makes the unpaid labour of women both cause and consequence of their economic dependence, related unfreedom, and a constraint on employment/income and economic independence. The need for such independence, in turn, is recognized by the women's movement, as an important precondition for opening up greater possibilities for social independence and freedom for women. Yet the evidence of conditions in paid or 'commercial employment' themselves promoting gender inequality has also mounted. Whether in the form of unequal wages, concentration of a relatively larger proportion of the female workforce in particularly low income/productive informal/unorganized forms of employment, gendered hierarchies within production units, or outright discrimination against employing women, etc., gender-based inequalities in the labour market are standard. This is apart from the double burden of unpaid domestic work alongside work for income from outside. Further, and particularly for women struggling against poverty, paid employment has also extended the boundaries of their subordination, and vulnerability, from within the patriarchal family to their situation as workers. Rarely and only tangentially are such employer interests driven by the needs and demands of women workers/employees themselves for decent wages/incomes/hours of work and conditions of life. Income-earning mass self-employment (thought by some to be a form of 'being your own boss') does not appear to have provided any better alternative to such wage employment in a world of sinking incomes from petty production and the inexorable march of integrated markets. With larger 
markets in an unregulated environment inevitably favouring larger entities, the incomes from petty selfemployment, already compressed by a crowd of small producer/seller competitors, are known to often fall below subsistence level (Ghosh 2006).

Ambiguity towards paid/income-earning labour and employment outside the purely family setting and related migration is subjectively perceived by women workers themselves, particularly from among the large majority of the labouring poor, who often associate their need for paid work and related migration with family poverty and other distress conditions, rather than as an avenue of emancipation from patriarchy. Nevertheless, despite such ambiguities, for an approach to labour migration as feeding the development and characteristics of labour markets, there is a clear case for focusing on paid work. However, from a women's movement perspective, a particular focus has to be maintained on the conditions in which women are being drawn into such paid work and its links with the broader economic growth processes, and it is the terms of employment that must hold centre stage in an approach to labour migration, rather than just celebration of the fact of employment and related migration/mobility.

In constructing our macro-view of the gender dimensions of labour migration based on the National Sample Survey on Migration in India 2007-08, we have therefore focused on paid labour. Two preliminary methodological points must be made. First, as has been only recently pointed out, the workforce data in the published reports of NSS can be misleading in terms of the extent of women's paid or incomeearning employment because of the inclusion of unpaid workers (albeit within the production boundary). The gross workforce figures that subsume unpaid and paid work into a common category are therefore inadequate for the purposes of assessing actual employment among women (Mazumdar/Neetha 20II). Unitlevel data from NSS do provide for some subcategories by employment/activity status, thus allowing for the separation of unpaid helpers from other workers (at least from among the self-employed). Such a separation makes it possible to focus on paid/incomeearning workers alone by excluding unpaid helpers from the calculation of the employed. ${ }^{19}$ We do this and have counted only paid/income-earning workers in the category of labour migrants/migrant workers. Our emphasis on paid/income-earning workers is for eliciting the gender structure of the labour market that is absorbing migrants and not a negation of the importance of the unpaid labour of women.
The second point relates to our counting of all migrants who are workers from among migrants defined by change of usual place of residence (UPR) and who have given reasons other than marriage for migration as labour migrants. ${ }^{20}$ Our reasoning is as follows: firstly, the majority of women workers who give marriage as their reason for migrating are workers, only in their immobile and local capacity as wives and daughters-in-law of the village they have married into. As such, when such marriage migrants are counted as migrant workers, the industrial distribution of all female workers after migration appears as virtually the same as the overall industrial distribution of the female workforce in the country. By including marriage migrants, it is neither possible to understand the relative importance of the sectors/industries driving/absorbing labour migrants, nor is it possible to distinguish migrant workers from immobile local workers in the case of women. In order to overcome such problems, we have reluctantly accepted that the present nature of the NSS data offer us little option but to exclude female marriage migrants from the frame, as a preliminary step towards identifying patterns of female labour migration. Elimination of some degree of labour migration camouflaged by marriage is to our minds a lesser error when compared with the immensely inflated picture of female labour mobility if all marriage migrants who are workers were counted as labour migrants.

Secondly, while those who gave 'employment' as their reason for migration may, of course, $a b$ initio be identified as employment/labour migrants, to our minds a better estimation could be made if all usual status paid/income-earning workers from among migrants by UPR, giving 'family movement', 'education', and 'other reasons' for migration, were also counted as labour migrants, since the nature of their employment may be presumed to be premised on their having moved from some other area of origin. The category of short-term migrants should also eo ipso be counted as labour migrants, since they are defined as

19 Broad activity status categories followed by the NSS are I) self-employed, 2) regular salaried workers, 3) casual labour. Among the self-employed, there are three subcategories - namely, 'own account worker', 'employer', and 'unpaid helper'. In order to arrive at paid/incomeearning workers, we have excluded the 'unpaid helpers' from the count.

20 Attempts to locate work-based migration by women have hitherto concentrated on the evidence of higher work participation rates after migration in the gross UPR based migration data (Shanthi 2006). 
Table 7.1: Estimated numbers of labour migrants in sectors/industries (All India, 2007-08). Source: Calculated from NSS Report No. 533 (64/10.2/2).

\begin{tabular}{|c|c|c|c|c|c|c|c|}
\hline \multirow[t]{2}{*}{ Industry } & \multicolumn{2}{|c|}{$\begin{array}{l}\text { Paid/income-earning } \\
\text { migrant workers } \\
\text { excluding migrants for } \\
\text { marriage (UPR) [000s] }\end{array}$} & \multicolumn{2}{|c|}{$\begin{array}{c}\text { Short-term migrants } \\
{[000 \mathrm{~s}]}\end{array}$} & \multicolumn{2}{|c|}{$\begin{array}{c}\text { Total labour migrants } \\
{[000 \mathrm{~s}]}\end{array}$} & \multirow[t]{2}{*}{$\begin{array}{c}\text { Female } \\
\text { share of } \\
\text { total } \\
{[\%]}\end{array}$} \\
\hline & Male & Female & Male & Female & Male & Female & \\
\hline $\begin{array}{l}\text { Agriculture, hunting, } \\
\text { forestry, fishing }\end{array}$ & $\begin{array}{c}6,430 \\
(14.53)\end{array}$ & $\begin{array}{c}2,399 \\
(31.74)\end{array}$ & $\begin{array}{c}2,449 \\
(19.32)\end{array}$ & $\begin{array}{c}922 \\
(43.47)\end{array}$ & $\begin{array}{c}8,879 \\
(15.60)\end{array}$ & $\begin{array}{c}3,321 \\
(34.31)\end{array}$ & 27.22 \\
\hline Construction & $\begin{array}{l}4,257 \\
(9.62)\end{array}$ & $\begin{array}{c}402 \\
(5.32)\end{array}$ & $\begin{array}{c}5,289 \\
(41.73)\end{array}$ & $\begin{array}{c}700 \\
(33.00)\end{array}$ & $\begin{array}{c}9,546 \\
(16.77)\end{array}$ & $\begin{array}{c}1,102 \\
(11.39)\end{array}$ & 10.35 \\
\hline $\begin{array}{l}\text { Mining, manufacturing, } \\
\text { electricity }\end{array}$ & $\begin{array}{l}11,258 \\
(25.44)\end{array}$ & $\begin{array}{c}1,575 \\
(20.84)\end{array}$ & $\begin{array}{c}2,412 \\
(19.03)\end{array}$ & $\begin{array}{c}306 \\
(14.43)\end{array}$ & $\begin{array}{l}13,670 \\
(24.01)\end{array}$ & $\begin{array}{c}1,881 \\
(19.44)\end{array}$ & 12.09 \\
\hline Trade, hotels, restaurants & $\begin{array}{c}8,027 \\
(18.14)\end{array}$ & $\begin{array}{c}474 \\
(6.27)\end{array}$ & $\begin{array}{r}1,190 \\
(9.39)\end{array}$ & $\begin{array}{c}32 \\
(1.51)\end{array}$ & $\begin{array}{c}9,217 \\
(16.19)\end{array}$ & $\begin{array}{c}506 \\
(5.23)\end{array}$ & 5.20 \\
\hline $\begin{array}{l}\text { All services other than } \\
\text { trade, hotels, restaurants* }\end{array}$ & $\begin{array}{l}14,280 \\
(32.27)\end{array}$ & $\begin{array}{c}2,698 \\
(35.70)\end{array}$ & $\begin{array}{c}1,338 \\
(10.56)\end{array}$ & $\begin{array}{c}161 \\
(7.59)\end{array}$ & $\begin{array}{r}15,618 \\
(27.44)\end{array}$ & $\begin{array}{c}2,859 \\
(29.54)\end{array}$ & 15.47 \\
\hline Total & $\begin{array}{c}44,252 \\
(100.00)\end{array}$ & $\begin{array}{c}7,556 \\
(100.00)\end{array}$ & $\begin{array}{c}12,675 \\
(100.00)\end{array}$ & $\begin{array}{c}2,121 \\
(100.00)\end{array}$ & $\begin{array}{c}56,927 \\
(100.00)\end{array}$ & $\begin{array}{c}9,677 \\
(100.00)\end{array}$ & 14.53 \\
\hline
\end{tabular}

* All services other than trade, etc. covers community, social and personal services, finance, real estate, and business services, as well as transport, storage, and communication.

Table 7.2: Share of migrants in India's paid/income-earning workforce (2007-08). Source: Calculated from NSS Reports Nos. $533(64 / 10.2 / 2)$ and $531(64 / 10.2 / 1)$.

\begin{tabular}{|c|c|c|c|c|c|}
\hline & \multicolumn{2}{|c|}{$\begin{array}{c}\text { Paid/income-earning } \\
\text { workforce } \\
{[000 s]}\end{array}$} & \multirow{2}{*}{$\begin{array}{c}\text { Share of female } \\
\text { workers in paid/ } \\
\text { income- earning } \\
\text { workforce } \\
{[\%]}\end{array}$} & \multicolumn{2}{|c|}{$\begin{array}{c}\text { Share of migrant } \\
\text { workers in paid/income- } \\
\text { earning workforce } \\
\text { by sex [\%] }\end{array}$} \\
\hline & Male & Female & & Male & Female \\
\hline Agriculture, hunting, forestry, fishing & $\begin{array}{l}132,467 \\
(46.62)\end{array}$ & $\begin{array}{l}53,266 \\
(65.05)\end{array}$ & 28.68 & 6.70 & 6.23 \\
\hline Construction & $\begin{array}{c}26,529 \\
(9.34)\end{array}$ & $\begin{array}{l}3,145 \\
(3.84)\end{array}$ & 10.60 & 35.98 & 35.05 \\
\hline Mining, manufacturing, electricity & $\begin{array}{l}37,725 \\
(13.28)\end{array}$ & $\begin{array}{l}10,452 \\
(12.76)\end{array}$ & 21.69 & 36.24 & 18.00 \\
\hline Trade, hotels, restaurants & $\begin{array}{l}36,748 \\
(12.93)\end{array}$ & $\begin{array}{l}2,838 \\
(3.47)\end{array}$ & 7.17 & 25.08 & 17.83 \\
\hline All services other than trade, etc. & $\begin{array}{l}49,494 \\
(17.42)\end{array}$ & $\begin{array}{c}12,141 \\
(14.83)\end{array}$ & 19.70 & 31.56 & 23.55 \\
\hline Total & $\begin{array}{c}284,112 \\
(100.00)\end{array}$ & $\begin{array}{c}81,881 \\
(100.00)\end{array}$ & 22.37 & 20.04 & 11.82 \\
\hline
\end{tabular}

those who did not change their UPR but undertook short-term movements and stayed away from their village/town for a period of one month or more but less than six months for employment or in search of employment. Despite the fact that that some underestimation of labour migration by women would still occur (because of the exclusion of those giving marriage as their reason for migration), we believe that the picture of the structure of labour migration that has been so constructed would broadly reflect the actual pattern.

From the 2007-08 NSS survey, the estimated total numbers of so-identified labour migrants in India were 66.6 million, of whom fifteen per cent were female (9.6 million). A little over eighteen per cent of 
the paid/income-earning workforce in the country were migrants. Table 7.I presents our estimations of the numbers of migrant workers of both categories (UPR and short-term) by sector/industry while table 7.2 gives the percentage of migrants in each sector/ industry.

As is obvious from table 7.I, agriculture is the single largest employer of female migrants, despite the fact that table 7.2 makes it apparent that the country's agricultural workforce (both male and female) is overwhelmingly non-migrant or local. Nevertheless, the greater significance of agriculture in the composition of female migration marks out one of the major structural differences between the pattern of female and male labour migration, further reflected in the higher share of women in migrant agricultural labour (27 per cent) than in any other industry/sector.

At the same time, the broad sector composition of female migration gives the impression of a fairly even distribution between agriculture at 34.3 per cent, industry (manufacturing, mining, and construction) at 30.8 per cent, and services (trade, etc., and all other services) at 34.8 per cent. Among male migrants, services at 43.6 per cent and industry at 40.8 per cent are far more dominant, leaving agriculture accounting for only 15.6 per cent of the male migrant workforce. In other words, non-agricultural employment was the destination of some 84.4 per cent of male migration and 65.6 per cent of female migration, within which services also appear to have become very significant among both male and female migrants.

The remarkably even distribution of female migrants across sectors ought not, however, to deflect attention from what we would consider to be the most salient gendered feature of the migratory pattern, namely the strong and relatively greater malecentric bias of migrant employment in both services and industry. Ninety-five per cent of all migrant workers in trade and eight-five per cent of those in other services were male. Men commanded eight-eight per cent of migrant jobs in manufacturing/mining and ninety per cent of the jobs in construction. Further, only in agriculture and construction is the share of women in migrant jobs roughly the same as their share of general employment. In all other major categories of industries/services, women's share of migrant jobs is less than their share of general employment. It thus appears that the impact of diversification of female employment through migration is of a far more limited nature than is initially suggested by the even distribution of female migrant workers across the three broad sectors of agriculture, industry, and services. In fact, the gender biases in the migratory pattern appear to be aggravating the biases against women in non-agricultural employment. A corollary to such aggravated bias is that while migration does seem to be having some impact on the structure and composition of the male workforce in the country, more specifically in raising the share of employment in other sectors relative to agriculture, its impact on the structure of the female workforce is of a far more limited nature - one of the reasons why, despite a fall in the numbers of women in agriculture, it still accounts for over sixty-five per cent of the female workforce in India. Given that the pattern of gross domestic product (GDP) growth has been towards a reduction in the share of agriculture to a mere fourteen per cent and an increase in the share of services to fifty-eight per cent and of industry to twenty-eight per cent, an aggravation of gender inequality in employment incomes is indeed indicated.

Apart from the sectoral structure of migration, an important question that has come from a range of field observations concerns the temporary nature of much of the migratory movement of labour. The 2007-08 NSS data suggest that the movement of roughly one-third of all labour migration in India was definitely temporary. Short-term migrants constituted some 2I per cent of male labour migration and 22 per cent of female labour migration, and some ro per cent of all UPR-based female migrants and 7 per cent of male migrants reported that their migration was temporary. Further, an acceleration in return migration is observable between 1993 and 2007-08 from I2.2 to I6.I per cent in the case of male migrants and from 4.4 to Io. 6 per cent in the case of female migrants. ${ }^{21}$ However, as evidenced in the CWDS field surveys, when a more worked-out typology of migration is applied, the actual proportions of temporary labour migrants among both men and women appear as far greater than the official macro-data suggest.

Although the NSS's 2007-08 migration survey has indeed proved somewhat amenable to providing a gendered picture of the sector composition of female labour migration, even apart from the persisting difficulty in arriving at more complete numbers of female labour migrants, there are several other issues and

21 The UPR figures here include not just labour migrantsthey include all workers and non-workers and paid and unpaid workers, but the somewhat common trend between men and women in temporary and return migration does indicate a link to the employment pattern. 
questions that have remained outside the pale of macro-surveys. Among them are the different types of migration, their characteristic features, the modes and manner of migration, the gender differentials, and the links between all of these and labour processes. The following sections of this chapter draw upon some of the findings of the CWDS primary surveys that focus on these questions, but first a few words of explanation of the method, rationale, and scope of the surveys.

\subsection{CWDS Gender and Migration Surveys: Constructing a Meso- level View}

The primary questions taken up by the CWDS surveys related to paid labour migration, and a key methodological issue that had to be addressed was whether the surveys should be directed at households or individuals. After an initial pilot round, it was decided to use two sets of questionnaires in tandem, one for collecting household characteristics, including some migration details of household members, and one for collecting more in-depth information on individual experiences of migration, including conditions of work.

A second question related to how the survey could be pitched at both the source and destination of migrants. Both were deemed necessary for a better understanding or comprehension of migration processes, including its compulsions, trajectories, and outcomes. As such, two categories of sites were taken for the questionnaire-based surveys: one comprising 'village sites', broadly representing source areas of migration (with room for including in-migrants to the village), and the second comprising a range of 'sector sites'. The latter targeted industries/occupations in primarily urban but also rural areas, where prior information indicated a concentration of women migrant workers. ${ }^{22}$

In the village sites, a village census preceded selection of a stratified sample of households, with social groups/caste categories as the primary axis, and perceived economic status as a secondary factor for sample selection. Since the focus was on migration, the

22 Two kinds of information guided the selection of sectors. The first was the employment patterns in urban areas based on NSS employment surveys, and the second was field-based information as to the sectors where women migrants were concentrated. selection process involved a major bias towards households with migrants (seventy per cent), and a minimum one-third quota for the specially marginalized castes/social groups, i.e., Scheduled Castes and Tribes. ${ }^{23}$ From these selected households, individual migrant workers were then selected, with a minimum quota of one-third of women.

In urban areas, broadly considered to be destination sites, only sector-based surveys were conducted based on a more flexible search for and purposive selection of only women migrants (opportunistic sampling). Thus, while several male migrants were covered by the questionnaire addressed to individual workers at village sites, in general they were excluded from the sector-based surveys.

The same questionnaires were used for village sites and sector sites, although differentiated methods of respondent selection were adopted. At the village sites, details of male and female members of all selected households were gathered, and individual migrants were drawn from the stratified household sample. However, where the entry was effected at the sector level, the household details followed from the selection of individual migrant worker respondents. Selection of both village and sector sites was done with an eye to dispersion among several states and an emphasis on prominent catchment areas of migrant labour recruitment or prominent destinations.

While such a method could not generate statistically validated macro-information, the utility of this meso-level view lies precisely in compensating for opacities or gaps in the available macro-statistics by adopting a more purposive site selection, as well as in upscaling micro-observations by introducing an intermediary level that incorporates greater spatial diversities and empirical breadth than do more localized micro-surveys.

Over a period of twenty-four months commencing in January 2009, surveys with the pair of common detailed and structured questionnaires were conducted across twenty of the country's twenty-eight states covering 5,007 individual migrants and 5,558 households. These were drawn from village surveys as well as sector-based surveys.

23 The quota for SC/ST was put in place because of our observation that women of these communities had a higher compulsion/propensity to be involved in labour migration. The minimum quota for individual women migrant workers could not however be filled everywhere, particularly in Uttar Pradesh and Bihar, which in a sense confirms the picture of male bias in labour migration observable in the macro-data. 
Figure 7.1: States where surveys were conducted named and coloured darker grey-rest of India lighter grey. Black dots indicate survey actual site locations. Source: The authors.

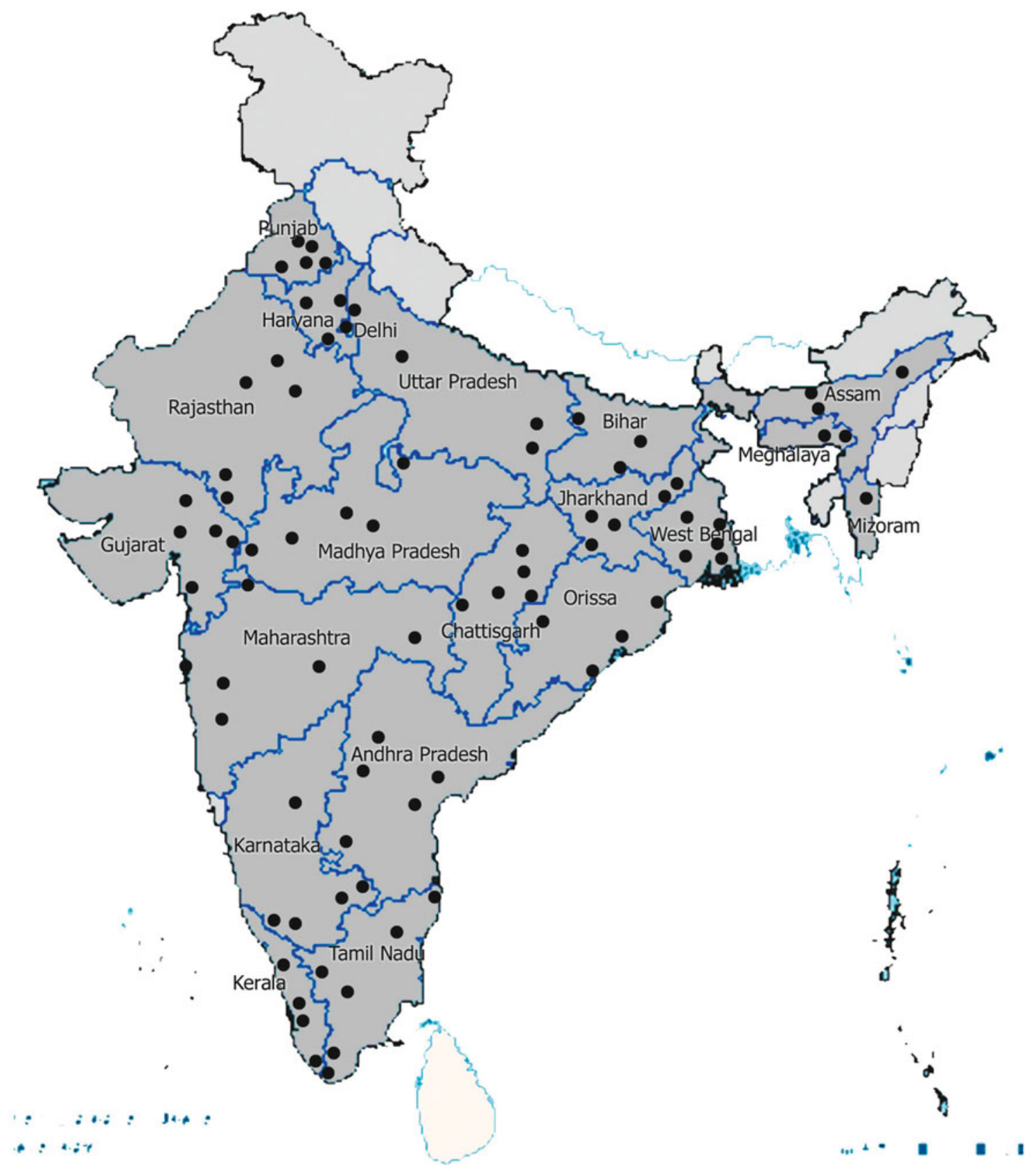

Comprehensive village surveys were conducted in thirty-five districts across seventeen states. Preliminary censuses covered I6, oro households in forty-three village sites, eliciting information on caste, relative economic status, and the number of economic migrants. These were followed by detailed questionnaires covering a total of 673 households without migrants and 2,564 individual migrants and their households. Of the individual migrants covered by the village surveys, I,903 were males and 66I were females.

Sector-based surveys directed at women migrant workers were conducted in twenty of the twenty-eight states, within which the urban areas covered consisted of seven large cities and ten medium-sized and smaller towns. Sector-based surveys covered 2,4I2 individual migrants and their households. 
In all, 3,073 female migrant workers and I,934 male migrant workers and their households were covered by the survey. Of the 3,073 women migrants, I,594 were surveyed in rural areas and I,479 in urban areas. In combination, the village- and sector-based migrant workers were accessed across more than seventy-five districts, apart from the seven large cities (including the three mega-cities of Mumbai, Delhi, and Kolkata). ${ }^{24}$

Whether regions/terrains should be classified into socio-cultural/historical, ecological, or agro-climatic zones for surveys on migration in India, a country with multiple scales of diversity, is still an open question for us. ${ }^{25}$ But for an idea of the mix that characterized the areas where this series of micro-surveys were located, we list the areas where the surveys were conducted and indicate them on the map.

They included

1. the agriculturally developed heartland of Malwa and Doaba regions of the state of Punjab; the developed but semi-arid western zone and eastern trans-Gangetic plains of Haryana; the upper Doab, Rohilkhand, and Purvanchal regions of the country's most populated state of Uttar Pradesh ${ }^{26}$ [all part of the landlocked north to north-west of the country];

2. the north-western, north-eastern as well as southern alluvial plains of the predominantly agricultural state of Bihar; the lateritic, red, and gravelly undulating region in the western part of West Bengal (eastern reaches of middle India's Chotanagpur plateau with a sizable tribal population), as well as the deltaic alluvial plains in the south of the state [north central and the coast of east India];

3. the ethnically highly diverse humid subtropical hills and valleys of the three states of Assam, Meghalaya, and Mizoram, [the north-east];

24 The other large cities were Bangalore, Chennai, Pune, and Ahmedabad.

25 The NSS divides each state into various regions, which are largely based on topographical/agro-climatic features.

26 Malwa in Punjab lies between the Sutlej and Yamuna rivers; its regional cultural history includes early mass conversion to Sikhism. Doaba is the tract of land between the confluence of the rivers Sutlej and Beas. In Uttar Pradesh, the Upper Doab refers to the western alluvial tracts between the rivers Ganga and Yamuna; Rohilkhand is on the upper plains of the Ganga; Purvanchal in eastern Uttar Pradesh is largely Bhojpuri-speaking.
4. the arid inland western parts as well as the coastal regions of Orissa state [east coast]; the newlyformed mineral rich states of Jharkhand and Chhattisgarh with large forest cover and tribal populations; the arid plains of Bundelkhand, the underdeveloped parts of the Malwa plateau area, and the agriculturally developed upper plains of the Narmada river basin in the country's second largest state of Madhya Pradesh [central highlands];

5. the semi-arid south-western reaches of the Aravalli Hills and sandy eastern plains in the physically largest state, Rajasthan [north-west India];

6. the significantly industrialized southern and the more backward north-eastern parts of the state of Gujarat; and in the otherwise most industrialized state of Maharashtra: Marathwada (west-central Deccan Plateau), Khandesh (north-western corner of the Deccan plateau with a significant tribal population) and the sugar cane belt in the southwest [western India];

7. the three cultural zones of the state of Andhra Pradesh - i.e., the semi-arid regions of Telengana and Rayalseema (eastern parts of the Deccan plateau) and the irrigated fertile coastal region of the state; the dry northern, torrid southern, and highly industrialized central parts of Tamilnadu; the Malabar coast in Kerala; and the fertile plains and slopes in the south as well as the northern arid regions of Karnataka [southern peninsula].

As it turned out, the survey sites were found to be located in thirteen of the fifteen agro-climatic zones in India, i.e., in the four zones of the Upper-Gangetic, Trans-Gangetic, Lower-Gangetic, and MiddleGangetic Plains, the four zones of the Eastern, Central, Western, and Southern Plateaus and Hills, the three zones of the East-Coast, West-Coast, and Gujarat Plains and Hills, the Western Dry Region, and the Eastern Himalayan Region. As such, the generalized findings are indeed of relevance in arriving at the big picture of gender and labour migration in India.

\subsection{Of Temporary and Permanent Migration: Developing a Typology}

The CWDS surveys applied a typology of migration that gave particular space to circularity, seasonality, contingency, and duration. Building on the range of observations garnered from earlier micro-studies and reports from the women's organizations, the typology 
evolved largely from pilot field observations. Based on such a typology, the household questionnaire generated data on types of migration for a total of 16,156 household members who were labour migrants, of whom 7,398 were female and 8,758 were male when the two categories of sites, sector-based and villagebased, were taken together. At a preliminary level, the most striking finding was the predominance of temporary migration among both men and women. Only forty-two per cent of women and thirty-six per cent of the men who were labour migrants in all the households covered by the surveys were long-term migrants, i.e., those who migrated for settlement at destination or who otherwise settled there. All others were various types of temporary migrants. The types of temporary migration became an area of special interest in this study. The large proportions of temporary migrants highlight the unsettled nature of the employment regime that is driving migration in contemporary India.

Circulatory migrants, i.e., those who migrate without any long-term workplace/residence at any particular destination and return to base for more than a month per year, appeared as the most significant type of temporary migration, comprising twenty per cent of the migrating women and twenty-three per cent of the male migrants in the households surveyed. These percentages include circulatory migrants of shorter duration (spells of less than four months) as well as of longer duration (more than four months). ${ }^{27}$ Around nine per cent of both male and female migrants were short-term seasonal migrants, i.e., those who migrate for work of a seasonal nature for a period ranging from a few days to around three months, and distinguished from circulatory in that they do not keep circulating back and forth, but spend most of the year at their base area. Two per cent of the female and three per cent of the male migrants were irregular short-term migrants, i.e., those migrating outside any established pattern or occupation, driven by abnormal contingencies/desperation rather than for any particular form or type of employment or seasonal demand for labour. Circulatory, short-term seasonal, and irregular short-term migration are all forms of short-term migration. The CWDS surveys suggest that

27 In the typology followed, a distinction was made between longer and shorter duration for circulatory migrants on the grounds that the experience of migration and related issues is somewhat different. From a broader perspective, however, both could be considered relatively short-term. the proportion of short-term migrants is roughly around one-third of male and female labour migration, significantly greater than the NSS estimates. It is the undercounting of short-term labour migration that, to our minds, is the key to the invisibilization of the 'armies of women' migrating for work.

Taking only the village sites, i.e., excluding the members of the households of women migrant workers in pre-selected sectors, the proportions of shortterm migrants actually increased, to 4I per cent among the women migrant workers and to 53 per cent among the male migrant workers. Circulatory migration increased to 24 per cent of labour migrants in the case of women and to 35 per cent in the case of men; short-term seasonal migrants increased to I4 per cent for women and I2 per cent for men; and irregular short-term movements rose to three per cent among women and five per cent among men. While this draws attention to the agrarian push as well as pullback involved in much short-term migration, several other processes are involved, including the absorption of semi-feudal patriarchal relations into the wage economy.

The second major type of temporary migration was medium-term, i.e., migration for employment/ work in any predetermined occupation/industry for a broadly fixed period of up to a few years. Among the women migrants of all households surveyed (village + sector), sixteen per cent were involved in mediumterm migration; among the men it was eighteen per cent. For the village sites alone, it is interesting that the proportions of medium-term migrants dropped sharply to nine per cent for women, but increased to twenty-one per cent for men. It appears that the points of origin among women migrant workers of medium term, particularly in urban areas, are more thinly dispersed across both rural and urban areas, and/or they are drawn/recruited from particular catchment pockets rather than by the more generalized kind of medium-term movement from village India that appears to be so significant in the pattern of male migration. Our sense was that the significance of medium-term migration is increasing, more so among male migrants, but also among female migrant workers in urban areas.

We turn next to the two other categories of migrants that are not normally included in labour migration, but were specially included in our typology thanks to discussions in the women's movement. One was long-distance commuters, i.e, those who commute across long distances (at least $50 \mathrm{~km}$ ) either daily or weekly, normally travelling to another district 
- from villages to towns/cities, from cities to rural areas, from one town to another town, etc. - all outside the perimeter of normal day-to-day movement for work within or around any village/town/city. The inclusion of commuting as a type of migration was based on early discussions within women's organizations about the phenomenon of the massing of women domestic workers in the trains coming from the rural interiors of districts in West Bengal to the city of Kolkata, leaving their homes as early as 3 or 4 a.m and returning late in the evening. Later, other reports also came in about women living in the towns of Maharashtra who undertake a reverse movement to rural areas for daily agricultural labour, although, compared to the Kolkata domestic workers, their commuting was for even less regular forms of employment (Sainath 2007). ${ }^{28}$ The same was observed during the pilot round in West Bengal, where women from the urbanized families of jute mill workers (an industry in endemic crisis) were seen commuting by trains till late at night for potato harvesting in rural areas more than $100 \mathrm{~km}$ from their residence, and that too for payment only in kind. Unable to afford the fare, many of the women commuters tend to travel without tickets, and are vulnerable to various types of harassment. Such commuting accounted for some six per cent of the women migrants when sector and village site households were combined, increasing by only one per cent from the universe of only village sites. Among men, it was significantly more from the village end at ten per cent, dropping to seven per cent in the combined universe. Of course, given the emphasis on households of only women migrant workers in the sector surveys, the male-female patterns are not strictly comparable when the sectors are included. Nevertheless, there is a suggestion that urban-to-rural commuting is perhaps of relatively greater proportions among women, a possibility that is supported by the evidence from NSS employment surveys of significantly higher proportions of urban women working in agriculture (Neetha/Mazumdar 2005).

The other specially included category was $m i$ grants for family care, i.e, those who migrate under the expectation (implicitly or explicitly) that they will perform various forms of unpaid care work for those who have migrated for employment. Separated from marriage migrants with unspecified purposes, migrants for family care accounted for four per cent of the women migrants when the households from sec-

28 The Hindu National Newspaper, 24 Jan 2007 - P. Sainath, 'It's been a hard day's night'. tors and village sites were combined, and five per cent in village sites alone. Given that the survey was primarily geared towards paid labour migration, the facets and patterns of migration for unpaid care work could not be elicited. There is need for further research in this area, which to our minds is significant for developing a greater understanding of how women's unpaid labour fits into circuits of migration. Some two per cent of the male migrants of the households in village sites also reported migrating for family care, perhaps because of responsibilities in relation to ageing parents, or even possibly wives and children. However, since the individual migrant questionnaires were not served on family care migrants, the surveys did not generate information on the question of the gendered features of such care and its implications.

\subsection{Types of Migration and Caste Hierarchies}

Types of migration are very closely correlated with particular sectors and occupations. Diversified service occupations, for example, are linked more with longterm and medium-term migration. Occupations based on hard manual labour, generally attached to degraded conditions of work, on the other hand, are more closely correlated with short-term and circular migration. At the same time, hierarchies of occupations in India also have a history of being correlated with caste hierarchies and other forms of marginalization of social groups such as adivasis (autochthonous tribal communities). At the time of adoption of the Indian constitution in 1950 , special provisions, including quota-based reservations in the legislatures, education, and government employment, were made for the members of castes that had for centuries been oppressed with the stigma of untouchability (dalits), recognized in the constitution as Scheduled Castes (SC), and similar provisions were made for marginalized tribal communities recognized as Scheduled Tribes (ST) ${ }^{29}$ Nevertheless, discrimination and marginalization based on their historical disadvantage has continued to resonate and even evolve to new levels.

29 Ninety per cent of the tribals live in tribal minority states spread over a broad girdle in middle India from Gujarat and Maharashtra in the west to West Bengal and Orissa in the east. The tribal majority states are all located in the north-east region of the country. Northeast tribals are, however, less than ten per cent of the total tribal population of India. 
Table 7.3: Distribution of types of migration of women workers within social groups/caste categories (\%). Source: The authors.

\begin{tabular}{|c|c|c|c|c|c|}
\hline Type of Migrant & $\begin{array}{c}\text { General }^{\mathrm{a}} \\
\text { (Upper } \\
\text { Castes) }\end{array}$ & $\mathrm{OBC}^{\mathrm{a}}$ & $\mathbf{M B C}^{\mathbf{b}}$ & $\mathrm{SC}^{\mathrm{c}}$ & $S T^{d}$ \\
\hline Long-term migrant & 44.51 & 41.56 & 21.51 & 25.98 & 20.81 \\
\hline Medium-term migrant & 30.02 & 22.98 & 30.11 & 17.36 & 10.48 \\
\hline Short-term seasonal migrant & 3.93 & 11.91 & 10.75 & 14.54 & 25.16 \\
\hline Irregular short-term migrant & 6.42 & 1.13 & 1.08 & 1.08 & 1.45 \\
\hline Circulatory migrant of longer duration & 2.90 & 9.93 & 5.38 & 19.52 & 22.10 \\
\hline Circulatory migrant of shorter duration & 4.55 & 6.95 & 4.30 & 6.06 & 10.00 \\
\hline Daily/weekly commuters & 4.97 & 3.69 & 25.81 & 14.67 & 8.71 \\
\hline Migrant for family care & 2.69 & 1.84 & 1.08 & 0.81 & 1.29 \\
\hline All & 100 & 100 & 100 & 100 & 100 \\
\hline All Short-term including Circulatory & 17.81 & 29.93 & 21.51 & 41.18 & 58.71 \\
\hline \multicolumn{6}{|c|}{$\begin{array}{l}\text { a The legal category of General does not declare caste status and includes all castes/communities not listed under } \\
\text { other categories. It however is mainly comprised of upper castes in all communities/religions. It includes many Mus- } \\
\text { lims, for they are distributed only between the General category and other backward classes/castes (OBC). } \\
\text { b MBC refers to a sub-category of OBC called Most backward castes. MBC is a category used only in some states. } \\
\text { c In the Indian constitution, Scheduled Castes do not include Christian or Muslim castes/communities who by origin/ } \\
\text { status face similar historical disadvantage and stigma as their counterparts among the Hindus. } \\
\text { d Like all other non-general categories, Scheduled Tribes are also listed at state levels and some may be listed as ST in } \\
\text { some states and as SC or OBC in others. There are distinct social differences between the } 90 \text { per cent of STs located } \\
\text { in middle India and the close to } 10 \text { per cent whose tribal origins lie in the north-east, including the fact that the middle } \\
\text { India STs are low-status minorities in all the states where they are located, while the STs of the north-east include } \\
\text { some majority communities in their respective states with exclusive rights over the land. This table includes STs from } \\
\text { the north-east, although the majority were from the middle India belt. }\end{array}$} \\
\hline
\end{tabular}

Violent atrocities on dalits and tribals have been an important concern of the contemporary women's movement since the I970s. However, it was through engagement with the growing agrarian crisis that the movement came to focus on the complexities of caste, class-, and gender-based violence with a betterdefined understanding. At the same time, the manner in which politics around caste erupted on the Indian political scene in the context of implementation of recommendations for reservation (in government employment and education) for the intermediate category of other backward classes/castes (OBCs) ${ }^{30}$ and violent upper-caste resistance and opposition to it subsequently ensured a place for caste and identity on the political canvas as never before. It also ensured that movements for women's equality could not, henceforth, be immune to the entrenched basis of caste-

30 Interestingly, one of the factors taken into account for identifying OBCs by the Mandal Commission was "castes/classes where participation of females in work is at least 25 per cent above the state average". based inequalities. Discussions on women's rights could not therefore ignore the assertion of social identities. While this gave a critical edge to movements for equality, mass-based women's organizations moved on to absorb the issues emerging from identity-based experience and assertion into their overall perspective of interrogation of social inequalities. From such a reconceptualized perspective, examination of the distribution of the relative shares of the various types of migration among female migrant workers of the various social group/caste categories brings interesting insights. Table 7.3 above presents such a distribution as it emerged from the CWDS survey of individual migrants. The table follows the official and legal categorization and listings of castes and communities.

A feature evident from the table is that among upper-caste women migrant workers the share of longterm and medium-term migration was predominant, with close to 75 per cent of them concentrated in long- and medium-term migration. In contrast, shortterm and circulatory migration accounted for around 
59 per cent of migrant women workers from scheduled tribes and 4I per cent of scheduled caste women migrants. The concentration of scheduled castes and tribes in this mass of general labour that circulates at the lower end of the productive economy, in which casual labour in agriculture, construction, and brickmaking figure prominently, draws attention to the present limitations of current migration, as conditioned by the prevailing economic and social system, in effecting the transformation of degrading feudal hierarchies.

When examining the more detailed occupational profiles of individual migrant workers, we found that sixty-six per cent of upper-caste female migrant workers were in the fairly diversified service sectors, as professional, technical, and related workers, call centre employees, sales workers in the more developed parts of the retail industry, nurses, office workers, and in other white-collar services. Further down the caste hierarchy there was progressively more concentration in hard manual-labour-based bhattas (brick kilns), seasonal agriculture, and paid domestic work. Migrant women workers from other backward castes/classes (OBC) were also relatively more concentrated in paid domestic and agricultural seasonal work although well over a third of them were distributed across various other services. Scheduled Caste (SC) women appeared to be more concentrated in brickmaking, while Scheduled Tribe (ST) migrant women were more concentrated in construction. ${ }^{31}$ The corollary of such concentrations of SC and ST women in manual occupations of a casual nature based on hard labour was their low proportion in white-collar services. White-collar services accounted for just nineteen per cent of SC and eighteen per cent of ST women migrant workers.

In contrast to these extremes separating workers across caste categories, paid domestic work occupied a significant place in the occupational profiles of women migrants of all caste categories, while textilebased manufacturing employment was fairly evenly present in all the categories, other than the ST category. As such, the indications are that concentration in migrant manual labour in agriculture, construction, and brickmaking at one end and access to diversified, relatively more settled, and white-collar forms of employment for migrants at the other are more determined by initial location in caste hierarchies. On the

31 More than 22 per cent of SC women migrants were in brickmaking while 28 per cent of ST women migrants were construction workers. other hand, gender, rather than caste lines, is obviously the primary axis that determines migration for paid domestic work.

\subsection{Patterns of Change in Women's Occupations through Migration: Diversification or Concentration?}

Four occupations dominated the profile of the women migrant workers who responded to the individual questionnaire-agriculture (I7.5 per cent), paid domestic work (I5.9 per cent), brickmaking (II.8 per cent), and construction (I4.3 per cent). The remaining forty per cent included vendors or petty traders, textile (spinning/tailoring/stitching) and other factory workers, home workers, sales workers in large malls as well as other shops, nurses in hospitals and other medical establishments, security guards and sanitation workers, beauticians, teachers in formal and informal educational institutions, call centre employees, a range of office workers, and professionals such as lawyers, doctors, journalists, and engineers. To get an idea of the pattern of occupational shifts and changes effected through migration, figures 7.2 and 7.3 present the occupations before and after their last or present round of migration for migrants with rural destinations, and figures 7.4 and 7.5 do the same for urban destinations.

In rural areas, the big story is the shift from a number of occupations (including in agriculture) to brickmaking. The share of brick kiln workers more than doubled from around nine per cent in the premigration profile of the workers to over twenty-one per cent post-migration. ${ }^{32}$ Such a concentration has several negative implications, particularly in relation to gender. Brickmaking in India is one of the most arduous manual occupations - involving softening of the soil/mud with water, digging out of the softened mud with a spade (generally done by males), packing the clay into moulds with hands, emptying them on the ground in rows (done by men and women), then stacking them for further drying in the sun (done by women and children). These workers (patheras) who

32 Estimates of the number of brick kilns in India vary from 50,000 to I00,000. According to World Bank sources, in 2010 brick production was estimated to be I40 billion per year, with production increasing 5-IO per cent a year. Estimates of the number of workers vary widely from 5-IO million to 25 million, of whom roughly 45 per cent are women. 
Figure 7.2: Occupations of women workers before migratiom. Rural destinations. Source: CWDS survey, Individual migrant questionnaire (village sites and sector sites combined).

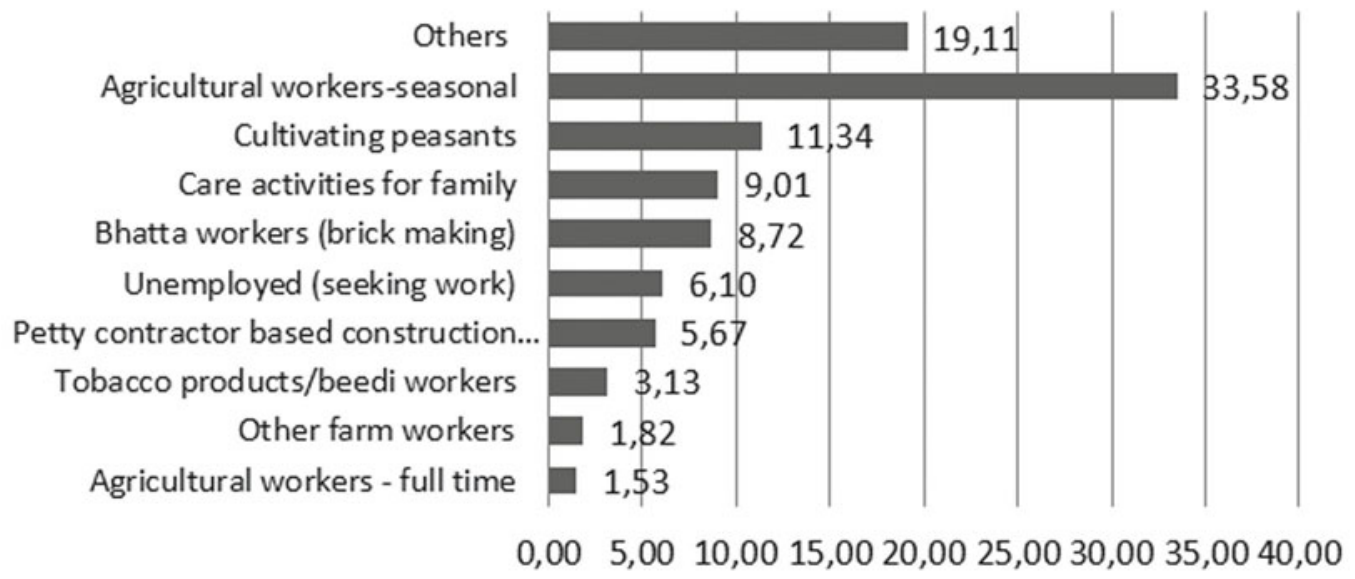

Figure 7.3: Occupations of women workers after migratiom. Rural destinations. Source: CWDS survey, Individual migrant questionnaire (village sites and sector sites combined)

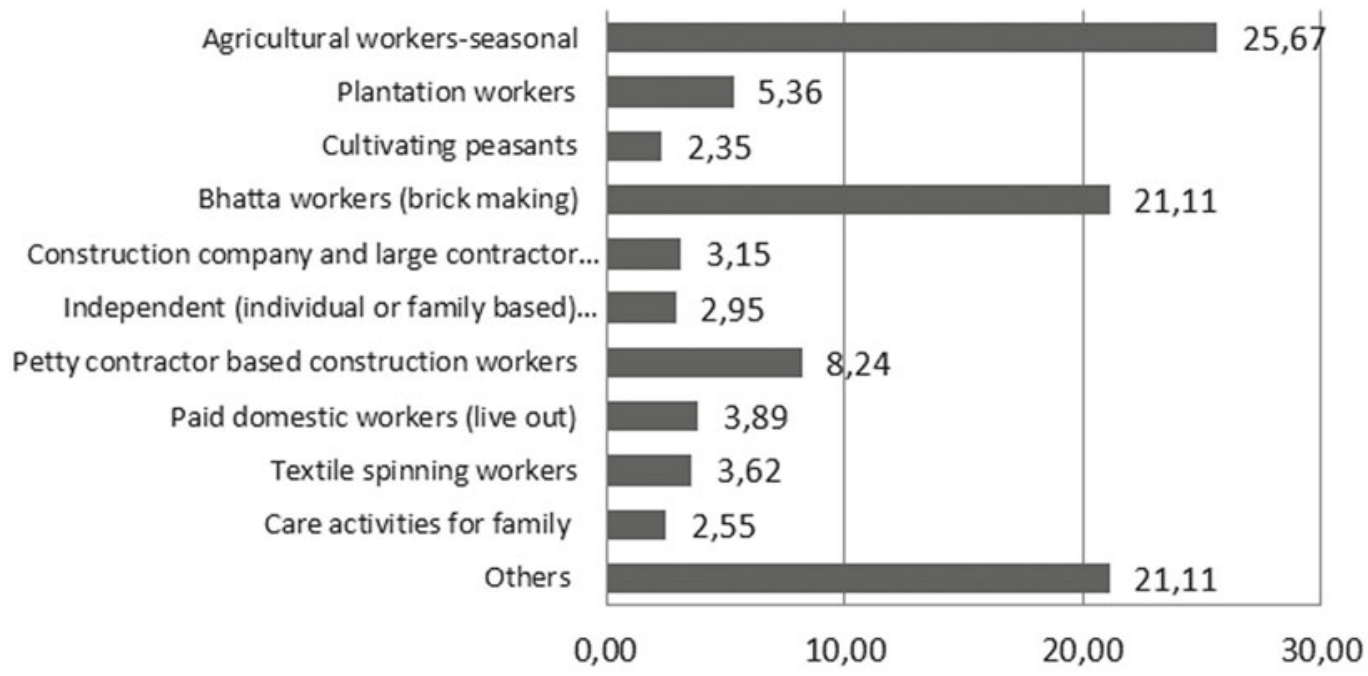

mould the raw bricks are recruited in male/female pairs (jodis). Specialized firers of the kilns, on the other hand, are always male and generally different from all other categories of brick workers in community and areas of origin. Other categories of workers include (with some permutations and combinations) those who manually carry and arrange the green bricks at the kiln (beldars) and those who manually carry the fully baked and cooled bricks to storage points (nikasis) - mostly women, recruited in male/ female groups, but not necessarily in pairs. All functions involve hard toil out in the open all day. Payment rates are fixed per I,000 bricks for all categories except the firers who have time-rated wages. The workers stay on site, at some distance from any village or other residential settlement, in rough temporary shacks, although some of the more long-standing and larger kilns have built single-room tenement lines.

Significant catchment areas for migrants in brickmaking are the drought-prone inland western parts of Orissa with high tribal concentrations, from where workers migrate to the southern states of Andhra Pradesh, Karnataka, and even Tamilnadu, though several districts in Tamilnadu are themselves recruiting grounds for Karnataka kilns. Kilns in West Bengal and Bihar draw workers from Jharkhand even as workers from Bihar travel eastwards and westwards to kilns in other states. From Rajasthan, Chhattisgarh, and now Uttar Pradesh, workers are taken to the kilns of Gujarat. Often it is assumed that the catchment areas are 
only economically backward and arid areas. Yet the green revolution belt of western Uttar Pradesh is perhaps one of the biggest suppliers of workers to the kilns across Punjab, Haryana, and other parts of Uttar Pradesh. Along with uneven regional development, it is inequities and iniquities within village India, the loss of artisanal occupations and the absence of other employment opportunities that has condemned large proportions particularly of dalits to conditions of dire poverty, even in developed regions, which in turn makes them amenable to migrating year after year to the brick kilns. The brickmaking season across the country generally falls within September/October to June, and with few exceptions it has become a completely migrant occupation. The predominant mode of recruitment is by labour contractors through the payment of advances to workers at the villages of origin, often well before the season begins. At the beginning and close of the season, railway stations close to the catchment areas in Orissa and districts on the Madhya Pradesh/Gujarat border can be seen packed with workers carrying their pots and pans and other daily necessities. If at the time of transportation to the kilns contractors' agents may be seen dealing with the police and facilitating passage, the worst situations arise during return journeys, when workers are abandoned to their own resources. Jam-packed into the trains as they are, there have even been cases of deaths through suffocation.

The hard labour involved in the circular migratory occupation of brickmaking, the fact that it virtually condemns women and men to a lifetime of six to eight months away from their homes every year, the fact that their children's education suffers, and the fact that it offers little potential for autonomy because the unit of labour is a family and wage payment is piece-rated - all indicate that although some survival may be ensured from this form of labour migration, it offers virtually no opportunity for social advancement or economic independence for women. Since brickmaking is included under manufacturing in the $\mathrm{Na}$ tional Industrial Classification (NIC), the shift from agriculture to brickmaking would appear in the macro-data as a shift to manufacturing and may be seen as diversification. The reality, is, however that labour migration to brick kilns and fields presages social immobility even as it involves permanent migratory circulation (Agnihotri/Mazumdar 2009). ${ }^{33}$

Agriculture including for plantations remains the largest occupational destination for rural women migrants and accounted for 33.4 per cent of rural female migrant workers in the CWDS surveys. However given its higher share in the pre-migration profile of the workers (48 per cent) it appears that although agriculture remains the most significant destination and in fact the share of women migrants in agriculture may be increasing (Venkateswarlu 2007), there is also a significant move away from agriculture in the rural migratory pattern. ${ }^{34}$ Agricultural migration is generally directed at pockets or regions of more developed or irrigated agriculture, but the streams of migration by women are more driven by other social factors. For example, women have not been a significant proportion of the large-scale migration streams from Bihar for agricultural labour in Punjab. On the other hand, prominent routes for women are from the rain-fed tribal pockets in the eastern parts of Jharkhand and southeast Bengal to the irrigated agriculturally developed paddy and potato areas of West Bengal, and from the upland Rajasthan/Gujarat/Madhya Pradesh border, which again has concentrations of tribal communities, to the cotton and groundnut fields in various parts of Gujarat. Young adolescent girls are particularly in demand for hybridized cottonseed farms (Bacillus thuringiensis, BT) that are linked through contracts to the major multinational corporation seed monopolies. ${ }^{35}$

Perhaps the most concentrated form of migration by women in agriculture is for sugar cane harvesting in western and southern India, for a much longer period than is commonly seen in seasonal agricultural work. Unlike in the other areas mentioned above, farmers themselves are not so involved in recruitment of migrants. ${ }^{36}$ It is the sugar mills (cooperatives as well as other private mills), rather than the farmers of Maharashtra, south Gujarat, and Karnataka, that use labour contractors to recruit workers for harvesting on the farms from which sugar cane is supplied. For these sugar cane cutters, the pattern of migratory life and work is of a longer duration than is otherwise seen in agricultural migration. It involves a significant

33 A striking instance of the scale of immobility observed in the field was the case of a young woman from Jharkhand in an advanced stage of pregnancy whom we met in a kiln located in north-east Bihar, and who had herself been born in a kiln where her mother had been working.

34 In figure 7.2 workers in agriculture before migration include seasonal agricultural labour, cultivating peasants, full-time agricultural workers, and other farm workers.

35 Gujarat has become a major centre for such cottonseed farms, although they are also found in Andhra Pradesh and Karnataka (Venkataswarlu). 
part of the year (generally October to May), and as in the case of brick kiln workers, there is little scope for social mobility, despite the use of modern factory production and accumulation systems. ${ }^{37}$ However, unlike brick workers, who generally work around one kiln in a season, cane cutters move from site to site within a single season, as a form of nomad labour. They are recruited in gangs, but again composed of male/female pairs, and wages are piece-rated (per tonne). The male/female pairs are referred to as koytas, which also refers to the sickle-like implement used for cutting the cane, and while the men cut the cane, the women bundle and carry it on their backs to whatever mode of transport is used by the mills. Without any fixed place to stay, these workers and their families are protected from the elements only by small tents that are pitched near wherever they may be working. They have even greater difficulties in accessing water and sanitation facilities than brick workers.

High-density routes that have been established for this male/female pair-based migration for sugar cane harvesting are I) from districts in Marathwada and $\mathrm{Vi-}$ darbha, Maharashtra to the southern districts in the same state that are home to the largest concentration of sugar mills in the country, 2) from the contiguous tribal belt along the borders of Maharashtra, Gujarat, and Madhya Pradesh to the sugar mills of Gujarat, and 3) from the north-eastern parts of Karnataka to the state's Belgaon Dharwad corridor adjacent to the sugar belt of Maharashtra, as well as to the agriculturally developed southern parts of the state (Mysore area) and even into Tamilnadu. ${ }^{38}$ Major communities involved in such migration include large concentrations of dalits, adivasis, and other backward castes, including some denotified tribes (DNT). ${ }^{39}$ In Maharash-

36 Second only to Brazil in cane sugar production, India is also the world's largest consumer of sugar. A total area of I. 8 million hectares is under cane sugar in Maharashtra, Karnataka, Gujarat, and Tamilanadu. Of the 566 sugar mills, 56 per cent are in the cooperative sector, 34 per cent in private hands, and the remainder in public ownership. Sugar cane is the third major crop after paddy and wheat and the second largest agro-processing industry after cotton and textiles.

37 Estimates of the number of such sugar cane cutters based on output and required labour inputs place the number of workers at one million in Maharashtra alone, of whom 70 per cent work in Maharashtra and 30 per cent in Gujarat.

38 In the north Indian state of Uttar Pradesh, the state that otherwise produces the largest share of the country's sugar cane, women are not, however, a part of migration for sugar cane harvesting. tra, even as their low wages for this backbreaking labour have become a regular source of agitation, sugar cane cutters recently waged a strike struggle against attempts to introduce the mechanical harvesters that would displace them from even such degraded conditions of employment. ${ }^{40}$

Two occupations that were absent in the pre-migration profile of any of these rural female migrants are noticeable. They are paid domestic work and textile spinning workers. The presence of migrants among rural domestic workers is a new phenomenon, and it is possible that they initially migrated for other occupations or in association with other migrant workers. The spinning mill workers, on the other hand, are recruited migrants, generally young and unmarried girls; for example in Tamilnadu girls have been recruited from the southern districts of the state for production work in spinning mills in the state's north central districts of Erode, Dindigul, Tirupur, and Coimbatore. For some years such labour recruitment operated under the guise of an apprenticeshipcum-marriage-assistance scheme, known as the 'Sumangali Marriage Scheme', whereby girls worked on a two-to-three-year contract with a spinning mill, at the end of which a lump sum was given to them purportedly for use in their marriage (read dowry). Since the girls were confined to residential camps run by the mill managements, it became known as a 'camp coolie system' and following a court order in 2007, decreeing it as 'bonded labour' and therefore illegal, the scheme as such has gone underground, although the pattern of migration it initiated does not appear to have changed. At the same time government district rural development agencies (DRDAs) seem to have become recruiters of young girls from districts such as Anantapur and Vizianagram in Andhra Pradesh and Ganjam, Orissa for spinning mills in ru-

39 Many of India's nomadic communities were notified as 'criminal tribes' by the British colonial regime through the infamous Criminal Tribes Act, I87I. After independence, they were denotified and are still referred to as Denotified Tribes (DNT), although they may be otherwise differentially classified as scheduled caste/tribe (SC/ST) or other backward class/caste (OBC) in various states of the country. See Government of India, National Advisory Council, Working Group on Denotified and Nomadic Tribes.

40 In 2008 , demanding higher wages, the union of cane cutters stopped the lorries coming to pick up workers at the beginning of the cane cutting season from entering Beed district. At the same time, a statewide agitation against the introduction of imported mechanized harvesters had been able to stop their use in most areas. 
ral parts of southern India. Some of these mills are state of the art in terms of technology, but located in rural isolation.

In urban areas, the patterns of employment are visibly more diversified. Rural-to-urban movement accounted for eighty per cent of the surveyed urban migrants. The pre-migration profile of the urban migrants indicated that around thirty per cent of the workers had been unemployed or engaged in only cooking, cleaning, and care activities for their families, and around one-third had been in agriculture, construction, and domestic work taken together. Thirtyseven per cent were in various diversified occupations even prior to their latest round of migration including some manufacturing workers, but mostly in a range of services. ${ }^{41}$ What is, however, the most striking feature of the transformation of occupations in rural-to-urban migration is the visible process of concentration in paid domestic work. The pre-migration profile of the urban women migrants shows that only around ten per cent were domestic workers. This share practically trebled to twenty-seven per cent in the post-migration profile. Arguably, the intensity of the process of concentration is part of an ongoing structuring of gender and class-based social hierarchies in urban India, in which the concentration of women workers in paid domestic work is emerging as a key element, a process that is to some extent being driven by migration from rural areas.

Domestic workers who 'live out', i.e., not with their employers, constitute the majority of such migrant domestic workers who generally migrate along with some family members. Among 'live in' domestic workers, who generally migrate singly, patterns of migration are being driven by contractor/agents (placement agencies) who have targeted tribal girls from Jharkhand and even plantation areas of West Bengal and Assam as their prime recruiting grounds. The average monthly wage for the live-out domestic workers was around three-quarters of the national floor for rural wages that has been established by the Mahatma Gandhi National Rural Employment Guarantee Scheme (MGNREGS) (the national floor being Rs 100, equivalent to slightly less than two dollars per day), while the live-in workers earned just about equivalent to the floor.

41 In the figures, the category of 'others', includes all occupations that were less than I.5 per cent of the sample, but actually covered a range of services in both rural and urban areas.
Three of the service occupations of these urban migrants were singularly absent in the pre-migration profiles of the workers, namely sales workers in retail outlets, beauticians/hairdressers, and call centre workers. Further, the share of manufacturing/production more than doubled from 5 per cent pre-migration to I2 per cent post-migration. The share of vendors/ petty traders also doubled from 2.6 per cent pre-migration to 6 per cent post-migration, and the share of nurses rose from 2.6 to 4.24 per cent. Apart from the above, the urban sample had some 36 per cent in more diverse services (including sales workers, beauticians, call centre workers, and professional/technicalrelated workers), whereas the pre-migration profile showed less than 27 per cent in diversified services.

Interestingly, among urban women migrants in construction, it appears that independent and petty-contractor-based construction (both in roughly equal measures) and large-scale companies are all involved in drawing women into urban construction activity. From around ten per cent before migration, the numbers in the post-migration urban sample had risen to fifteen per cent. The greater presence of independent construction workers indicates that the migration of these workers to urban areas was perhaps less contractor-driven in comparison to rural areas and more based on independent expectations of finding employment.

But the most significant change effected by migration to urban areas that needs to be highlighted is that thirty-one per cent of the surveyed women workers who were unemployed or involved in only familybased domestic duties (in a sense housewives) before migration were able to effect entry into paid employment in urban areas. At the same time, it is noticeable that only around fourteen per cent of the urban workers had actually made a transition from agricultural to non-agricultural employment. This reinforces the point that emerged from the NSS data that female labour migration is not leading to a large-scale structural shift of the female workforce out of agriculture. However, the reasons for the fact that only a small proportion of urban migrant women workers are being drawn from the agricultural workforce, and a much larger proportion are being drawn from unemployed or hitherto housebound women, perhaps need to be located in the different attitudes that control or direct women's involvement in relation to paid employment according to feudal caste and status hierarchies. It is well known that upper-caste women were traditionally restricted from working outside the home, and certainly less involved in the manual la- 
Figure 7.4: Occupation pattern of female migrant workers before migratiom (Urban) [\%]. Source: CWDS survey, individual migrant questionnaire (village sites and sector sites combined).

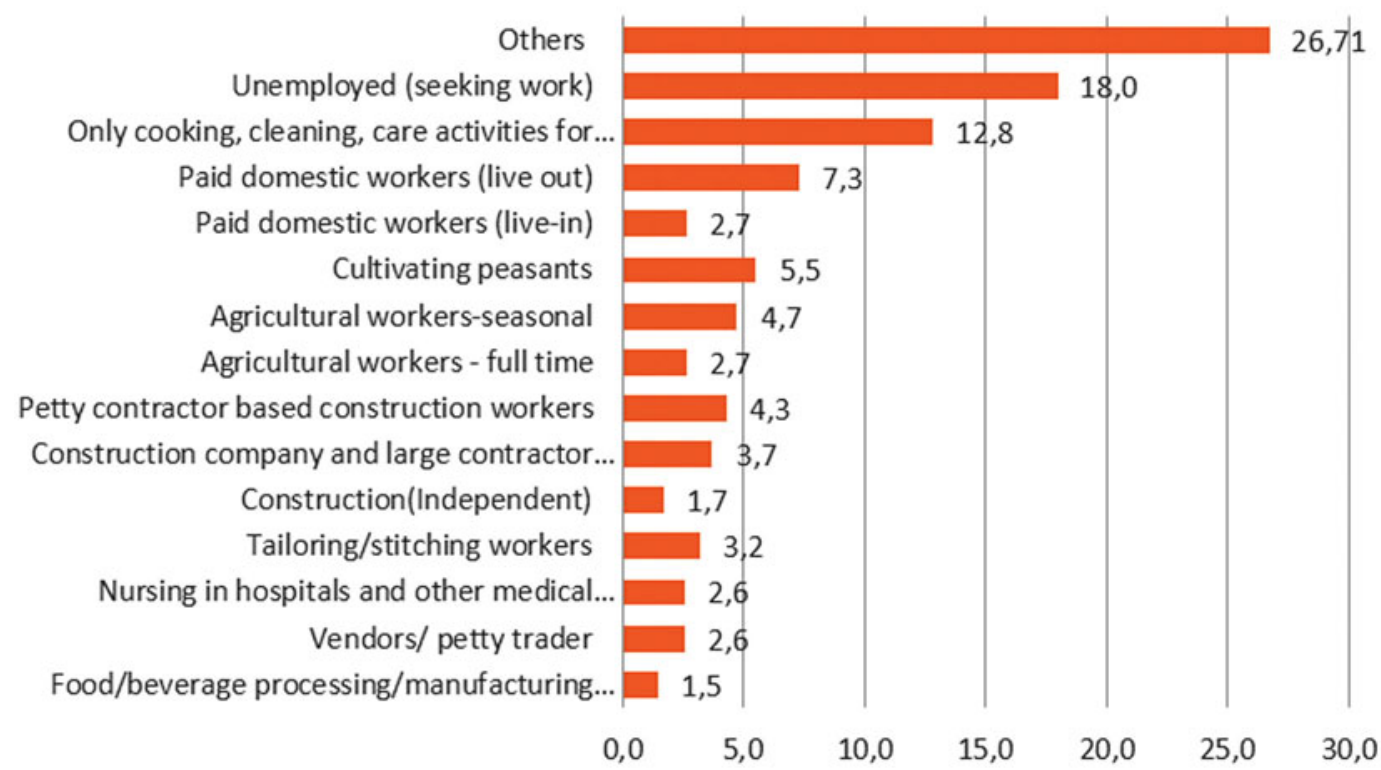

Figure 7.5: Occupation pattern of female migrant workers after migratiom (Urban) [\%]. Source: CWDS survey, individual migrant questionnaire (village sites and sector sites combined).

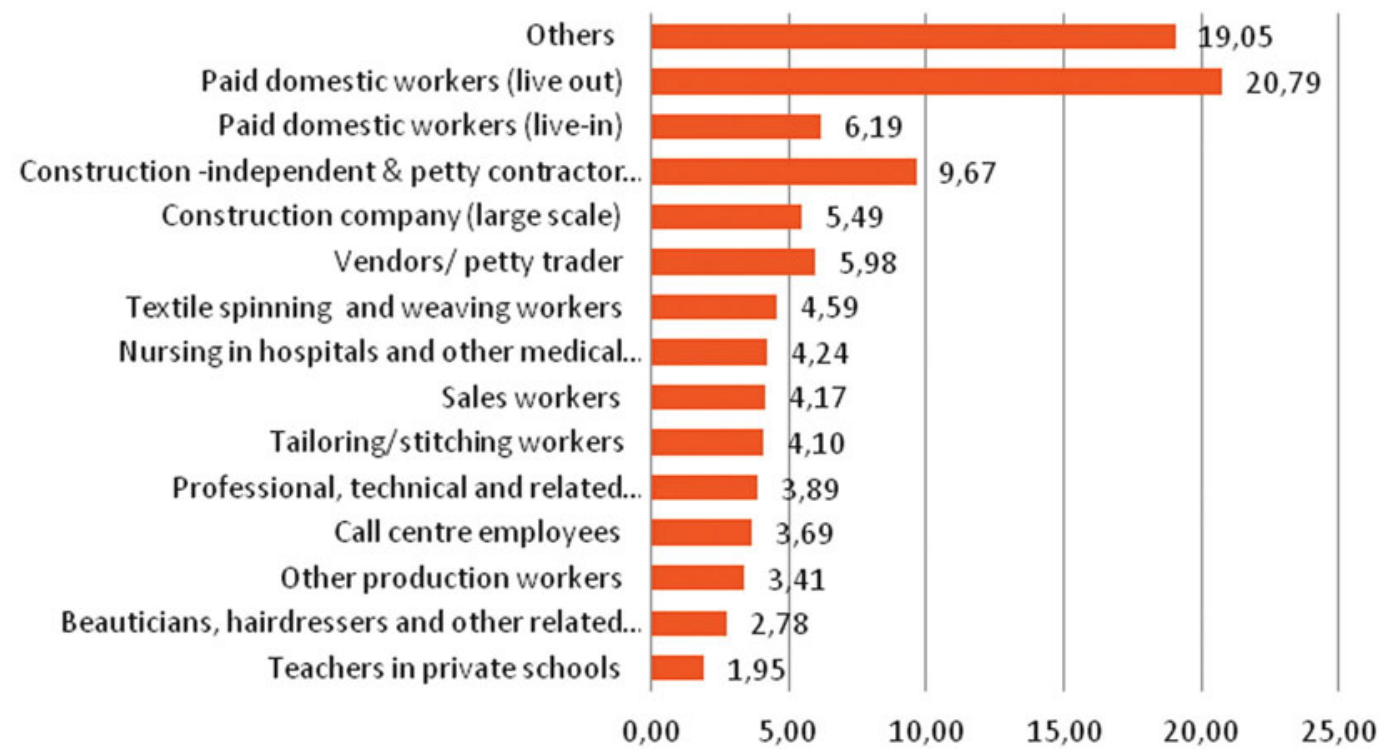

bour associated with agriculture. Conversely, lower social and caste status compels greater involvement of women in paid work in agriculture. The more diversified and less stigmatized service occupations that have developed in urban areas have clearly opened up more opportunities for hitherto more restricted upper-caste women than for traditional female workers in agriculture, who are more drawn more from SC, ST, and even OBC backgrounds.

\subsection{Of Contractors and Independence: Modes and Manner of Migration.}

Interestingly, information gathered on the mode of migration, given in figure 7.6 indicates the prevalence of strong independent motivation in labour migration by women in both rural and urban migration streams. Such independence is substantially greater among ur- 
ban women migrant workers (80.7 per cent). Of course, this independent mode of migration also includes decisions taken by couples/nuclear families and not necessarily in a purely individual capacity. This becomes clear from the manner of their migration given in figure figure 7.7 which shows that the largest category is of women who migrated with only family members (43.2 per cent) in contrast to men among whom the largest category is of those who have migrated alone (42.7 per cent). ${ }^{42}$

Nevertheless, it is significant that a great majority of the female migrant workers in both rural and urban areas felt a degree of involvement in decisions related to their migration. The CWDS field surveys indicate that the overwhelming majority of the women workers migrated with clear intentions of finding employment, including perhaps even some of those who otherwise moved for associational reasons. Further, the fact that almost a quarter (close to twenty-three per cent) of female migrant workers reported that they have migrated alone indicates that 'autonomous' migration by women is on the rise. With another seven per cent of female migrants indicating that they migrated in all-female groups, autonomous migration by women for employment, particularly in urban areas, is a phenomenon that can no longer be ignored.

At the same time, employer or contractor mobilization of workers is significant in rural female labour migration. ${ }^{43}$ Some twenty-five per cent of rural women migrant workers were mobilized by contractors (figure 7.6). Here some separation has been made between local and outside contractors, although given the prevalence of tiers among contractors, it is probable that at least some of the local contractors were themselves mobilized by outside agents.

Within mobilization by contractors, the dominance of the outside contractor/agent/employer is clear, particularly in migration for brick kilns (bhattas) and agriculture and in some cases for construction. Among urban women migrant workers, however, only

42 Among women migrant workers, even among the over 24 per cent who migrated in mixed male and female groups, there were many who had migrated with husbands.

43 The lineages of the contractor regime for recruiting/ mobilizing/controlling workers for manual labour in India go back to forced labour in colonial times-its continuing exploitative nature long recognized by labour law in the country, which is why the abolition of contract labour (defined in Indian law as employment through a contractor) has been a long-standing demand of the labour movement. a little over six per cent were mobilized by contractor, but even here the outside contractor is slightly more of a factor than the local. Among such workers mobilized by contractors were women who had migrated alone or in all-female groups, raising questions as to how appropriate it would be to assume that they are all autonomous migrants. The greater role of non-local contractors in the mobilization of women workers also runs counter to the common assumption that the relationship between women and contractors is based on kin or local/social associations. It remains true that the nature of contractor-driven migration, which is often based on advances given well before actual migration, often leads to forms of debt bondage

The Inter-state Migrant Workmen's Act, 1979 (the only labour law that specifically addresses migrant workers) was designed to provide for some worker entitlements in precisely such contractor-driven modes of migration (although only for those who cross state boundaries). It has remained the most ineffectual of all the labour laws, as has repeatedly been pointed out (2nd Labour Commission 2002; NCEUS 2007). It stipulates that transportation and related costs have to be borne by contractors, and that wages should be paid for even the journey time. It also has provisions for a displacement allowance, apart from other provisions for ensuring decent conditions of work. But this law is known more for its violation than its implementation and does not even apply to intra-state migration. In practice the advance from employers for movement costs is treated as a loan, so that workers have to pay it off through their labour; our fieldwork showed that indeed the amount advanced to them was generally deducted from their wages at the end of the migration round.

\subsection{Concluding Remarks}

This chapter has attempted to highlight some of the most neglected and hitherto poorly delineated dimensions of internal labour migration in India from a perspective drawn from the experiences of the contemporary women's movement in the country. The CWDS research project on which it is based has been distinctive in trying to cover not just one or a few corners of India; it attempted to reflect as far as possible the entire current picture. As such, the chapter's main arguments and findings - summarized below - concern tens of millions of diverse women moving within a billion-plus country of sub-continental proportions. 
Figure 7.6: Mode of last migration by women migrant workers (\% distribution). Source: CWDS survey, individual migrant questionnaire (village sites and sector sites combined).

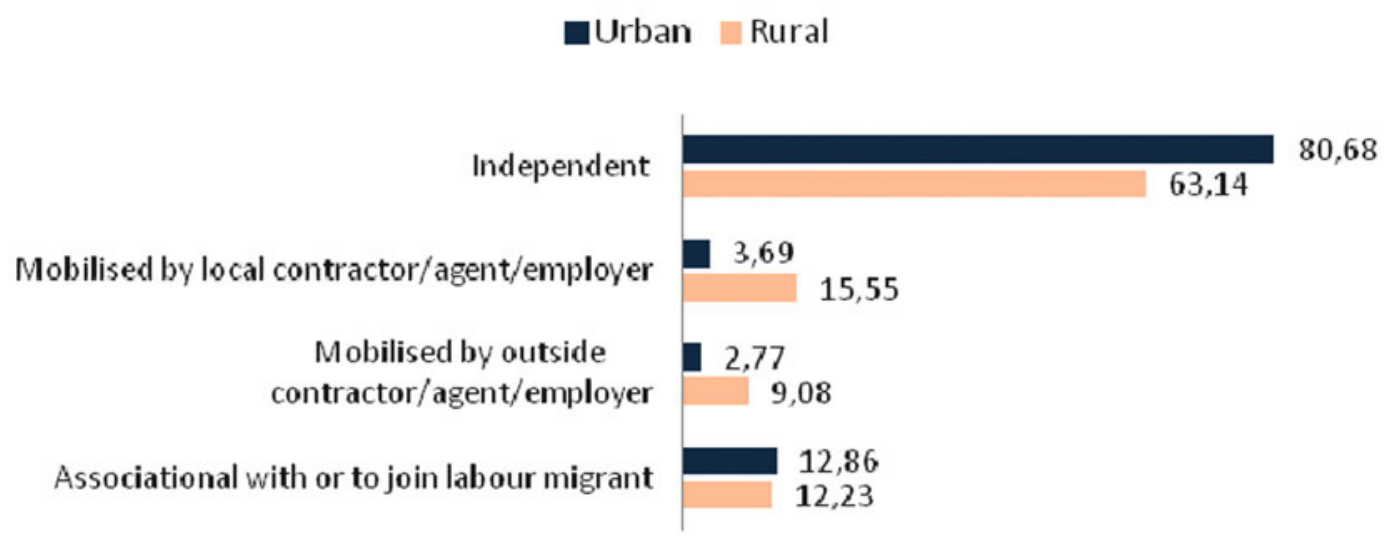

Figure 7.7: Manner of last migration (\% distribution). Source: CWDS survey, individual migrant questionnaire (village sites and sector sites combined).

\section{Female $\square$ Male}

\section{Gone with only family members \\ Gone in mixed male and female group

$$
\text { Gone alone }
$$
Gone in all female group
Others (specify) \\ Gone in all male group}

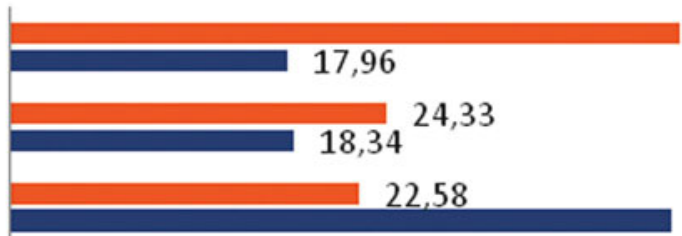

43,25
At a general level, the findings of primary surveys conducted by the CWDS from 2009 to $201 \mathrm{I}$ using a socially grounded typology of migration provide a meso-level view of the predominance of the temporary in contemporary labour migration, including medium-term and circular labour migration. Temporary migration is shown to be a more significant phenomenon than is indicated in the available macro-data for both men and women. As such, the primary research findings posit the need for reorientation away from the present conceptual dominance of a permanent settlement paradigm in the official macrosurveys, and greater recognition of different types of temporary migration in the concepts and definitions adopted. We argue that the macro-level underestimation of short-term and circular labour migration is a most significant factor in invisibilizing much of women's labour migration in India.
Regarding the social direction of the patterns of women's labour migration in India, the meso-level view from this research project provides the following major findings.

- There is strong evidence that migration has led to only limited diversification of women's employment, in precisely the period when the country's higher levels of particularly service-driven growth had become the most celebrated topic of Indian development discourse.

- The empirical evidence indicates occupational shifts through migration leading to greater concentration of women in a relatively narrow band of occupations, often with limited scope for social advancement, generally differentiated however along the fault lines of entrenched social hierarchies based on caste and community. 
- It shows more medium-term and long-term migration among women workers from upper-caste communities accompanying relatively greater levels of diversification of their employment into various types of services in urban areas.

- At the other extreme is the concentration of migrant women workers from the historically disadvantaged and stigmatized communities of scheduled castes and tribes in short-term and particularly circular migration for hard manual labour with little scope for social advancement.

- At the same time, while a distinctive movement towards concentration of women in paid domestic work, particularly through rural-to-urban migration, cuts across all castes/tribes/communities, textile-based factory production also appears relatively less characterized by caste features, having drawn migrant women from all communities other than scheduled tribes.

- Further, in some circular migration-based employment regimes with high levels of female density, such as brickmaking across the country and sugar cane cutting in western and southern India, women's wage work in the capital-accumulationoriented modern sector is itself subsumed in labouring units comprised of male/female pairs or family units. When such subsumption is combined with piece rates, not only is there no scope for independent work/activity and income, but indeed legal quantification of the value of individual women's work becomes an insurmountable problem. This is compounded by a cycle of advances and debt-based tying of such labouring units that means that while survival may be ensured by such modes of migration, the possibilities of social advancement are severely limited.

The macro- and meso-level findings as laid out in this chapter challenge some assumptions that have become commonplace in approaches to women's work and work-based migration.

- On the one hand, the low shares of women in labour migration for industry and diversified services run counter to the assumption that liberalization and globalization leads to feminization of labour and to related migration. In fact, the escalated devaluation of women's traditional work appears to be confronted with employment constriction and a narrow range of options, rather than compensation for loss of earlier employment through adequate expansion and diversification in paid employment opportunities for women.
- Overall, female labour migration has had less of an impact on the structure of the female workforce in comparison to men, reflected in the continuing and relatively greater concentration of women in agriculture and in low employment rates among urban women, evident in the macro-statistics.

- It appears that such a continuing weight of agriculture in the structure of the female workforce is also partly maintained because relatively smaller proportions of women migrant workers in urban areas have been drawn from the agricultural workforce; instead more of them (particularly from the higher castes) have made a transition from nonemployment to employment.

- Both the macro-data and the village sites component in the CWDS meso-level study indicate an extreme degree of male bias in migration-based employment in industry and services (less so in agriculture) at levels even greater than in non-migrant employment. It is argued that the pattern of migration in India is actually enhancing structural gender inequalities in the labour market, and needs to be correlated to the massive reduction in the absolute numbers and employment share of the female workforce, evident in the official workforce statistics for 2007-08 and 2009-IO.

The fact that the above findings are for a period of high growth in India raises several additional questions. Obviously such growth, characterized by a rapidly declining share of agriculture in the country's GDP and accelerated growth primarily in services and to a lesser extent also in industry, has not generated commensurate demand in terms of employment, for which women have paid the main price of reduced employment. Despite the push towards migration from distress induced by the agrarian crisis, a pullback also appears to be operating, linked to the predominantly temporary nature of the developing employment regime, and the widespread inability of the migrant workforce (male and female) circulating at the lower ends of the economy to sustain social reproduction without periodic retreat to the village economy, even as the village economy is not providing sufficient employment. As such, the overall analysis implicitly draws attention to the need to bring into the debate questions related to structural limitations to the migration enterprise under the current growth path: limitations in effecting a) durable or structural occupational shifts away from agriculture for women workers, b) escape from or transformation of degrading semi-feudal social relations based on caste hierarchies and patriarchy, and c) escape from the massive employment crisis 
that women are now facing in India.

Nevertheless, the urge to change the conditions of their life and work is evident in the high proportion of women migrant workers declaring that they themselves decided to migrate, whether in families or independently. This, combined with a significant presence of autonomous migration by women, does indeed indicate a wave of social assertion and aspirational motivation, so important for the advance of the women's movement. Yet the overall findings of the CWDS study show that structural constraints shaped by macro-processes under neo-liberal-driven economic growth have narrowed the field of opportunity for women's work-based migration and indeed sometimes reinforced entrenched patriarchies.
While focusing on the empirical features of female labour migration in India, the chapter's emphasis on a gendering of the issues and questions from a women's movement perspective has foregrounded the intersections between gender, caste, and class differentials and inequalities that are reflected in migration patterns in contemporary India. The social outcome of much of female labour migration does not appear to be moving towards the lessening of such differentials; and even demand-driven migration patterns appear to be reconfiguring and providing new foundations for inequalities. Our study thus highlights the need for a redistributive and equalizing growth agenda for the country, a demand for which the women's movement in India has been among the most active advocates.

\section{Annex}

Table 7.4: Location of CWDS survey sites. Source: The authors.

\begin{tabular}{|c|c|c|}
\hline $\begin{array}{l}\text { Geographic region in } \\
\text { India }\end{array}$ & States - subregions & Districts/ metropolitan cities \\
\hline \multirow[t]{2}{*}{ North to north-west } & $\begin{array}{l}\text { Punjab - Malwa lies between the Sutlej and Yamuna } \\
\text { rivers; its regional cultural history includes early mass } \\
\text { conversion to Sikhism, and Doaba, the tract of land } \\
\text { between the confluence of the rivers Sutlej and Beas }\end{array}$ & $\begin{array}{l}\text { Districts: Bathinda, Sangrur, Patiala, } \\
\text { Jalandhar, Ludhiana }\end{array}$ \\
\hline & $\begin{array}{l}\text { Haryana - semi-arid western zone and eastern trans- } \\
\text { Gangetic plains }\end{array}$ & Districts: Hisar, Rewari, Panipat \\
\hline \multirow[t]{4}{*}{$\begin{array}{l}\text { North-central to east } \\
\text { coast }\end{array}$} & $\begin{array}{l}\text { Uttar Pradesh - Upper Doab, western alluvial tracts } \\
\text { between the rivers Ganga and Yamuna, Rohilkhand, } \\
\text { on the upper plains of the Ganga so named because } \\
\text { of the rule of Rohilla Pathans established in Mughal } \\
\text { times. Purvanchal, eastern Uttar Pradesh, largely Bhoj- } \\
\text { puri-speaking }\end{array}$ & $\begin{array}{l}\text { Districts: Baghpat, Badayun, Varanasi, } \\
\text { Azamgarh }\end{array}$ \\
\hline & $\begin{array}{l}\text { Bihar - north-western and southern alluvial plains of } \\
\text { this predominantly agricultural state }\end{array}$ & Districts: Siwan, Begusarai, Nawada \\
\hline & $\begin{array}{l}\text { West Bengal - the lateritic, red, and gravelly undulating } \\
\text { region in the west (eastern reaches of middle India's } \\
\text { Chotanagpur plateau with a sizeable tribal population) } \\
\text { and deltaic alluvial plains in the south of the state }\end{array}$ & $\begin{array}{l}\text { Districts: West Medinipur, North } 24 \\
\text { Parganas, South } 24 \text { Parganas, Bardha- } \\
\text { man }\end{array}$ \\
\hline & $\begin{array}{l}\text { Orissa - the arid inland western parts as well as the } \\
\text { coastal regions }\end{array}$ & $\begin{array}{l}\text { Districts: Balangir, Khorda, Bhadrak, } \\
\text { Ganjam }\end{array}$ \\
\hline \multirow[t]{2}{*}{ North-east } & $\begin{array}{l}\text { Assam - warm, humid, lower and upper Brahmaputra } \\
\text { valleys }\end{array}$ & Districts: Kamrup, Nalbari, Dibrugarh \\
\hline & Meghalaya and Mizoram-humid subtropical hills & $\begin{array}{l}\text { Districts: East Khasi Hills, Jaintia Hills, } \\
\text { Aizawl }\end{array}$ \\
\hline
\end{tabular}




\begin{tabular}{|c|c|c|}
\hline $\begin{array}{l}\text { Geographic region in } \\
\text { India }\end{array}$ & States - subregions & Districts/ metropolitan cities \\
\hline \multirow[t]{4}{*}{$\begin{array}{l}\text { Central Highlands to } \\
\text { north-west }\end{array}$} & $\begin{array}{l}\text { Jharkhand - Chotanagpur plateau south of the Indo- } \\
\text { Gangetic plan with a large tribal population. Dry, sub- } \\
\text { tropical climate }\end{array}$ & $\begin{array}{l}\text { Districts: Ranchi, Lohardagga, Gumla, } \\
\text { Dumka, Jamtara }\end{array}$ \\
\hline & $\begin{array}{l}\text { Chhattisgarh - Plains region between the 'Northern } \\
\text { hilly region' in the north and the 'Bastar plateau' in the } \\
\text { south of the state }\end{array}$ & $\begin{array}{l}\text { Districts: Korba, Janjgir-Champa, Rajn- } \\
\text { andgaon, Raipur, Mahasamund }\end{array}$ \\
\hline & $\begin{array}{l}\text { Madhya Pradesh - arid plains of Bundelkhand (Uttar } \\
\text { Pradesh border), the Malwa plateau area, and agricul- } \\
\text { turally developed upper plains of the Narmada river } \\
\text { basin }\end{array}$ & $\begin{array}{l}\text { Districts: Tikamgarh, Jhabua, Indore, } \\
\text { Bhopal, Raisen }\end{array}$ \\
\hline & $\begin{array}{l}\text { Rajasthan - semi-arid southwestern reaches of the } \\
\text { Aravalli Hills and sandy eastern plains }\end{array}$ & $\begin{array}{l}\text { Districts: Udaipur, Dungarpur, Nagaur, } \\
\text { Sikar, Jaipur }\end{array}$ \\
\hline \multirow[t]{2}{*}{ Western Region } & $\begin{array}{l}\text { Gujarat - the significantly industrialized southern and } \\
\text { the more backward north eastern parts }\end{array}$ & $\begin{array}{l}\text { Districts: Surat, Ahmedabad, Gand- } \\
\text { hinagar, Mehsana, Dahod, Panchmahal }\end{array}$ \\
\hline & $\begin{array}{l}\text { Maharashtra - rain shadow region of Marathwada, the } \\
\text { coal belt of Vidarbha, Khandesh (south of the Satpura } \\
\text { range with a significant tribal population), and the } \\
\text { concentrated sugar cane belt in the south-west of the } \\
\text { state }\end{array}$ & $\begin{array}{l}\text { Districts: Parbhani, Chandrapur, } \\
\text { Nandurbar, Satara, }\end{array}$ \\
\hline \multirow[t]{4}{*}{ Southern Peninsula } & $\begin{array}{l}\text { Karnataka - the fertile plains and slopes in the south } \\
\text { as well as the northern arid regions }\end{array}$ & $\begin{array}{l}\text { Districts: Mysore, Kodagu, Kolar, } \\
\text { Koppal }\end{array}$ \\
\hline & $\begin{array}{l}\text { Andhra Pradesh - semi-arid regions of Telengana and } \\
\text { Rayalseema (southern plateau) and the irrigated fertile } \\
\text { coastal region that constitute three cultural zones of } \\
\text { the state }\end{array}$ & $\begin{array}{l}\text { Mehboobnagar, Anantapur, Guntur, } \\
\text { Prakasam }\end{array}$ \\
\hline & $\begin{array}{l}\text { Tamilnadu - the dry northern, torrid southern, and } \\
\text { highly industrialized central parts }\end{array}$ & $\begin{array}{l}\text { Districts: Villupuram, Dindigul, Tirunel- } \\
\text { veli, Kanya Kumari, Tirupur }\end{array}$ \\
\hline & $\begin{array}{l}\text { Kerala - the Malabar coast in the north of the state as } \\
\text { well as southern and central parts of the erstwhile } \\
\text { state of Travancore-Cochin }\end{array}$ & $\begin{array}{l}\text { Districts: Mallapuram, Ernakulam, Kot- } \\
\text { tayam, Trivandrum }\end{array}$ \\
\hline Metropolitan cities & $\begin{array}{l}\text { NCT of Delhi (city state), Maharashtra, West Bengal, } \\
\text { Karnataka, Tamilnadu }\end{array}$ & $\begin{array}{l}\text { Cities: Delhi, Mumbai, Kolkata, Banga- } \\
\text { lore, Chennai, Hyderabad, Pune, }\end{array}$ \\
\hline
\end{tabular}

\section{References}

Agnihotri, Indu, 200I: "Re-reading histories", Seminar, 505, at: <http://www.india-seminar.com/cd8899/cd_frame 8899.html>.

Agnihotri, Indu; Mazumdar, Indrani, 2009: "Dusty Trails and Unsettled Lives: Women's Labour Migration in Rural India”, in: Indian Journal of Gender Studies, I6 (September/December): 375-399.

AIDWA (All India Democratic Women's Association), 2003: Expanding Dimensions of Dowry (New Delhi: Publisher).

Banerjee, Narayan; Ray, Lokenath, I99I: "Seasonal Migration: A Case Study from West Bengal”, New Delhi: Centre for Women's Development Studies (Mimeo).

Bangasser, Paul E., 2000: The ILO and the informal sector: an institutional history, ILO Employment Paper, 2000/ 9 (Geneva: ILO).
Breman, Jan, 1996: Footloose Labour: Working in India's Informal Sector (Cambridge: Cambridge University Press).

Centre for Women's Development Studies, 2005: "Globalization and the Women's Movement in India, Seminar report”, 2005, at: <http://www.cwds.org/occasional papers.htm> and <http://www.cwds.ac.in/OCPaper/ GlobalisationReport.pdf $>$.

Chaudhry, S; Devi Mohan, T.; Devi, T.; 20II. "Of Marriage and Migration: Bengali and Bihari brides in a UP Village”, in: Indian Journal of Gender Studies, I8,3 (October): $3 \mathrm{II}-340$.

Elson, Diane, 200I: "For an Emancipatory Socioeconomics" (Geneva: UNRISD), at: <http://www.unrisd.org/ $80256 \mathrm{~B}_{3} \mathrm{Coo}_{5} \mathrm{BCCF} 9 /$ (httpPublications)/o3BA6AogBE 6 E42D8Ci256BC900453D9B?OpenDocument>.

Ghosh, Jayati, 2005: Trade Liberalization in Agriculture: An Examination of Impact and Policy Strategies with Spe- 
cial Reference to India (New York: UNDP, Human Development Report Office, Occasional Paper I2).

Ghosh, Jayati, 2006: "Being your own boss", in: Frontline, 23,23 (Nov. I8-Dec. OI).

Hugo, Graeme, 2003: "Circular Migration: Keeping Development Rolling?”, at: <http://www.migrationinformation.org/feature/display.cfm?ID=I29>.

Karat, Brinda, 2005: "Neo-liberal Agendas and Rural Women's Concerns", in: Globalization and the Women's Movement in India (New Delhi: Centre for Women's Development Studies): 2I-26.

Karlekar, Malavika, 1995: "Gender Dimensions in Labour Migration - An Overview”, in: Schenk-Sandbergen, Loes (Ed.): Women and Seasonal Labour Migration (New Delhi: Sage).

Kundu, Amitabh, 1999: Urban Informal Sector in India: Macro Trends and Policy Perspectives. Issues in Development, Discussion Paper 25 (Geneva: ILO).

Mazumdar, Indrani; Neetha, N., 20II: "Gender dimensions: Employment trends in India, I993-94 to 2009-IO”, in: Economic and Political Weekly, XLVI,43.

Menon, A.; Vadivelu, G. A., 2006: "Common Property Resources in Different Agro-Climatic Landscapes in India”, in: Conservation \& Society, 4: I32-I54.

Mosse, David; Gupta, Sanjeev; Mehta, Mona; Shah, Vidya; Rees, Julia [KRIBP Project Team, 2002: "Brokered Livelihoods: Debt, Labour Migration and Development in Tribal Western India”, in: Journal of Development Studies, 38,5: 59-88.

NCEUS (National Commission for Enterprises in the Unorganised Sector), 2007: Report on the Conditions of Work and Promotion of Livelihoods in the Unorganised Sector (New Delhi: Government of India, NCEUS).

Neetha, N.; Mazumdar, Indrani, 2005: "New developments in labour hiring and employment in urban India" (Mimeo) (New Delhi. Centre for Women's Development Studies).

NSS (National Sample Survey) Office, 20Io: Employment and Unemployment Situation in India 2007-2008. NSS Report 53I, NSS 64 ${ }^{\text {th }}$ Round (64/IO.2/I) (New Delhi: Government of India, Ministry of Statistics \& Programme Implementation).
NSS (National Sample Survey) Office, 20I0: Migration in India: 2007-2008, NSS Report 533, NSS $64^{\text {th }}$ Round (64/Io.2/2) (New Delhi: Government of India, Ministry of Statistics \& Programme Implementation).

NSS (National Sample Survey) Office, Migration in India, I993, I999-2000, 2007-2008; Employment and Unemployment Survey Reports, I993-I994, I999-2000, 2004-2005, 2007-2008, and 2009-2010. Various Rounds (New Delhi: Government of India, Ministry of Statistics \& Programme Implementation).

Rao, M.S.A. (Ed), I986: Studies in Migration (Delhi: Manohar).

Rawal, Vikas, 2006: “The Labour Process in Rural Haryana (India): A Field-Report from Two Villages”, in: Journal of Agrarian Change, 6,4 (October): 538-583.

Sainath, P., 2007: “It's been hard day's night", in: The Hindu National Newspaper, 24 January 2007; at: <http://www. hindu.com/2007/oI/24/stories/20070I2404621300. htm>.

Schenk-Sandbergen, Loes (Ed.) I995: Women and Seasonal Labour Migration (New Delhi: Sage).

Second National Commission on Labour, Report, 2002, (New Delhi: Govt. of India, Ministry of Labour).

Shanthi, K., 2006: Female Labour Migration in India: Insights from NSSO Data, WP-o4. (city: Madras School of Economics),

Sheel, Ranjana, 1997: The Political Economy of Dowry (New Delhi: Manohar).

Srivastava, Ravi, 2005: "Internal Migration Links with Poverty and Development, Country", Regional Conference on Migration and Development in Asia, Lanzhou, China (Mimeo). (London: DFID).

Teerink, Rensje, I995: "Migration and Its Impact on Khandeshi Women in the Sugar Cane Harvest", in: Schenk-Sandbergen, Loes (Ed.): Women and seasonal labour migration (New Delhi: Sage).

Venkateswarlu, Davuluri, 2007: "Recent Trends in Employment of Child Labour in Hybrid Cottonseed Production in India” (Mimeo) (Hyderabad: Glocal Research and Consultancy Services).

Open Access. This chapter is distributed under the terms of the Creative Commons Attribution Non-commercial License, which permits any noncommercial use, distribution, and reproduction in any medium, provided the original author(s) and source are credited. 